Working Paper \#002/2020

\title{
Investment Timing and Social Welfare under Feed-in Tariff Contract
}

\author{
Luciana Barbosa \\ CICEE - Research Center in Business and Economics, Universidade Autónoma de Lisboa \\ Artur Rodrigues \\ NIPE and Scholl of Economics and Management, University of Minho
}

Alberto Sardinha

INESC-ID and Instituto Superior Técnico, Universidade de Lisboa

\begin{abstract}
This paper presents a novel model to analyze the effects on the investment timing and social welfare of three feed-in tariffs (FIT) within an oligopolistic market structure. The FIT contracts are the fixed price, the fixed premium, and the minimum price guarantee. The model allows the identification of the optimal time to deploy a renewable energy project and the value of the tariff that maximizes the social welfare for each FIT design. These optimal tariffs generate the same investment timing and the same social welfare.
\end{abstract}

Keywords: Investment Analysis; Real Options; Feed-In-Tariffs; Uncertainty; Social Welfare; Duopolistic Markets

JEL classification: L94, Q42, Q72 


\title{
Investment Timing and Social Welfare under Feed-in Tariff Contract Schemes
}

\author{
Luciana Barbosa $^{\mathrm{a}}$, Artur Rodrigues ${ }^{\mathrm{b}}$, and Alberto Sardinha ${ }^{\mathrm{c}}$ \\ ${ }^{a}$ CICEE - Research Center in Business and Economics, Universidade Autónoma de Lisboa \\ ${ }^{b}$ NIPE and School of Economics and Management, University of Minho \\ ${ }^{c}$ INESC-ID and Instituto Superior Técnico, Universidade de Lisboa
}

March 13, 2020

\begin{abstract}
This paper presents a novel model to analyze the effects on the investment timing and social welfare of three feed-in tariffs (FIT) within an oligopolistic market structure. The FIT contracts are the fixed price, the fixed premium, and the minimum price guarantee. The model allows the identification of the optimal time to deploy a renewable energy project and the value of the tariff that maximizes the social welfare for each FIT design. These optimal tariffs generate the same investment timing and the same social welfare.
\end{abstract}

JEL Classification: L94; Q42; C72.

Keywords: Real Options; Feed-in tariffs; Uncertainty; Social Welfare; Duopolistic Markets. 


\section{Introduction}

Creating incentives for renewable energy generation has been on the agenda of many governments for over 20 years. This is due to the fact that the investment in many renewable energy technologies are capital intensive. Renewable energy policies are aimed at not only accelerating the investment decisions but also increasing the social welfare. One of the most popular policy schemes for accelerating investment in renewable energy projects is the feed-in tariff (FIT) program (REN21 2018). A FIT policy has two key features, namely a contract with a long duration (e.g., 20 years) and remuneration for the production of renewable energy. Over the years, FIT policies have evolved into many different price-based incentives.

Couture \& Gagnon (2010) propose a classification of FIT policies into two groups. The first group is called market-independent FITs because the remuneration is independent from the electricity market price. The FIT schemes in the second group have premium payments that are added to the electricity market price, thus creating a premium policy or market-dependent FIT. For many years, market-independent FITs have been offered in many jurisdictions due to its low-risk nature. On the other hand, market-dependent FITs may have a higher risk, but they also have embedded options that provide managerial flexibilities and may generate higher revenues. Moreover, they create incentives to increase production in times of high demand and when the electricity price is high.

This article presents a novel model to analyze FIT contracts from both the marketindependent and market-dependent FIT schemes within an oligopoly. The two marketdependent FITs are the minimum price guarantee and fixed premium, and the marketindependent FIT is the fixed price. In particular, we combine an asymmetric Stackelberg model with an analytical real options framework in order to calculate the optimal investment threshold, the social welfare, and the optimal tariff that maximizes the social welfare. Based on the model, we analyze the impact of the value of the remuneration, the duration of the contract and the volatility on the investment threshold and social welfare.

The results show that the three FITs accelerate investment when the value of the tariff increases. In addition, increasing the duration of the contract also accelerates the investment decision for FITs with a fixed premium and minimum price guarantee. However, fixed-price FITs only accelerate investment when the value of the tariff is above a threshold. As expected, increasing the market uncertainty postpones the investment decision.

We also draw the following conclusions from the social welfare analysis. First, all FIT schemes have the same investment trigger when maximizing the social welfare, and generate the same social welfare. Second, policies may have a greater impact on the social welfare when society considers a higher value for the cost of the environmental damage. Third, the duration of the FIT scheme does not change the maximum attainable welfare and other parameters, such as market uncertainty and demand elasticity, can produce non-monotonic effects. Finally, our results suggest that in markets with more inelastic demand functions, like the energy markets, an optimal designed FIT is relatively smaller, inducing later investment and smaller increments in the social welfare.

This paper is organized as follows. Section 2 presents the literature review and our main contributions to literature. Section 3 presents the models for all types of FIT schemes, namely a minimum price guarantee, fixed premium and fixed price. Sections 5.1 and 5.2 present a comparative statics analysis of the investment threshold and so- 
cial welfare for all types of FIT schemes, respectively. Finally, Section 6 presents the concluding remarks.

\section{Literature review}

Our work relates and contributes to literature in three strands of work, namely game theory models for energy markets, social welfare analysis of renewable energy policies, and real options applied to renewable energy support schemes. We present each strand below and state our key contributions.

\subsection{Game theory models for energy markets}

Several papers have used game theory in energy markets. For instance, Wolfram (1999) analyzes the market power of generation companies in the British electricity market, and shows that prices are lower than estimates due to many reasons, such as entry deterrence and actions from the regulator. Chuang, Wu \& Varaiya (2001) formulate a Cournot oligopoly market for generation expansion planning, and present numerical results to analyze industry expansion, generation investment and trends. Murphy \& Smeers (2005) present an open-loop and closed-loop Cournot model, in which investment and power dispatch decisions occur simultaneously in the former model and in two stages in the latter model; in addition, this work compares both models with a perfect competition. Nanduri, Das \& Rocha (2009) utilize a similar single stage Cournot model as Murphy \& Smeers (2005) taking into consideration the network transmission constraints. Twomey \& Neuhoff (2010) examine the case of intermittent generation return under perfect competition, monopoly and oligopoly; the results show that, when different technologies are used, the market participants benefit differently from the increased price. Moreover, intermittent technologies benefit less from the market power effect than conventional technologies.

Some of these works are focused on analyzing policy schemes, such as FITs. For example, Chang, Hu \& Han (2013) use a Stackelberg game to analyze the social welfare of a fixed-price FIT contract in Taiwan, and the results show that the consumer surplus always increases but the social welfare may decrease under certain conditions. Devine, Farrell \& Lee (2017) use a Stackelberg model to find an optimal FIT design that efficiently divides market risk between investors and policymaker. Yi, Xin-gang, Yu-zhuo \& Ying (2019) apply evolutionary game theory to analyze policy decisions that create incentives for producers to switch from FITs to Renewable Portfolio Standards.

While the aforementioned research works use game theory to model energy markets and to analyze policy schemes, none of these works focus on how FITs can affect the timing of investment decisions.

\subsection{Social welfare analysis of renewable energy policies}

The social welfare analysis has also been used in previous works to compare different renewable energy policy schemes. For example, Tamás, Shrestha \& Zhou (2010) compare the social welfare of a fixed-price FIT and tradable green certificate schemes. Based on data from the U.K., the authors conclude that the tradable green certificates generate a higher social welfare. Yamamoto (2012) analyzes the social welfare for 3 different policy schemes, namely a fixed-price FIT, net-metering, and net purchase and sale. The FIT 
scheme generates the higher social welfare when the amount of reduction in electricity consumption is small. Pirnia, Nathwani \& Fuller (2011) presents a social welfare analysis of a fixed-price FIT in Ontario, Canada. The results show that the FIT policy generates a lower social welfare than a scenario without a FIT policy, because there is a reasonable amount of wealth transferred from consumers to producers with a FIT policy. Sun \& yan Nie (2015) compare a fixed-price FIT with a renewable portfolio standard policy and analyze the effect of these policy schemes on the social welfare. The results are unable determine the support scheme that generates the highest social welfare because both policies depend on the level of negative externalities, such as pollution damage. Yamamoto (2017) presents a model to analyze a fixed-price FIT in combination with capital subsidies with an aim to increase the adoption of residential photovoltaic systems. This work also analyzes the impact of the combined policy schemes on the social welfare. The social welfare is maximized when the FIT tariff is equal to the avoided cost per unit and the capital subsidies are set at a level that can control the number of adopters.

Despite the interesting analyses of the impact of the renewable energy policy schemes on the social welfare, none of the research works above have taken into consideration the option to invest and consequently the timing effect of these policy schemes on the investment decision and the social welfare.

\subsection{Real options applied to renewable energy support schemes}

Merton (1973) is responsible for laying an important foundation for the option-pricing methodology and turning it into a popular technique for scholars and practitioners. The real options approach (Dixit \& Pindyck 1994) use the financial option-pricing methodology to value investments in real assets. Similar to financial options, a real option is a right but not an obligation to invest, wait, expand, or abandon a project, while information changes due to uncertainties. Hence, the corporate finance literature saw the potential of using the techniques of option pricing to value real investment projects. While the work from Myers (1977) was the first to coin the term real options, it was Tourinho (1979) that first used the option-pricing methodology to value the option to extract natural resources under market uncertainty.

In the corporate world, managers still rely on the popular net present value (NPV) methodology to value real investments because it is based on a simple rule: "invest now if NPV is greater than zero". However, many scholars (e.g., McDonald \& Siegel (1986)) have shown that the NPV methodology yields a lower value of the project because it does not take into consideration the value of the options (i.e., managerial flexibilities) and uncertainties. In other words, the NPV methodology does not consider typical behaviors within the investment decision-making process, such as the option to defer investment and the option to gather information regarding the evolution of market uncertainty. Rocha, Salles, Garcia, Sardinha \& Teixeira (2007) present a case study of the real options methodology applied to housing investment. The results show that the methodology can improve the analysis and improve the decision-making process.

Regarding real options research applied to renewable energy investments, Ceseña, Mutale \& Rivas-Dávalos (2013) present a survey of several research works that use the real options approach to analyze energy generation projects, with special focus on renewable energy projects. The survey concludes that many opportunities are still available for applying the real options methodology. In particular, the survey states that the real options can be a useful approach for analyzing the effectiveness of renewable energy 
policies.

We thus focus on the real options research that analyzes the effectiveness of renewable energy policies. Kim \& Lee (2012) analyze the number of sign-ups in different market conditions, with a real options numerical technique. The analysis aims to compare four FITs, namely a fixed price, a fixed premium, a minimum price guarantee, and a sliding premium. The numerical analysis, however, reaches the conclusion that a dominant policy schemes does not exist when considering the number of sign-ups, burden on ratepayers, and total capacity installed. Abadie \& Chamorro (2014) also use a real options numerical technique in order to analyze investment timing of policy schemes, namely a fixed-price FIT, a fixed-premium FIT, and renewable obligation certificates. The results show that the policy schemes can accelerate investment, especially compared to a scenario with no subsidy available. Boomsma, Meade \& Fleten (2012) analyze renewable energy investments with three support schemes with an analytical approach. The policy schemes are the fixed-price FIT, a fixed-premium FIT and renewable energy certificate trading. The results suggest that the renewable energy certificate trading is the best subsidy for larger projects while fixed-price FIT is well suited for accelerating investment. Barbosa, Ferrão, Rodrigues \& Sardinha (2018) use an analytical approach to analyze a FIT with a minimum price guarantee under market and policy uncertainty. When comparing the scenarios with and without policy uncertainty, the results show that the policy uncertainty can accelerate investment. Although the aim of our work is also to compare different FIT policies, we use an analytical real options framework to analyze the support schemes within an oligopoly, while all the research works above consider a price-taker scenario. We can thus derive the optimal investment threshold and analyze the impact of the investment decision on the social welfare.

In summary, to the best of our knowledge, this paper presents the first research work to employ an analytical real options framework to derive market-independent and marketdependent FITs within an oligopolistic market. In particular, we derive the optimal investment threshold of FIT contracts with a finite duration, which is a more realistic assumption. In addition, we analyze the impact of the FIT schemes on the social welfare and calculate the optimal tariff in order to draw conclusions to policymakers.

\section{Renewable energy producers in oligopolies}

Twomey \& Neuhoff (2010) state that modeling energy markets as oligopolies is probably the most appropriate assumption, because many markets are neither a monopoly nor a perfect competition. We thus analyze different FIT schemes within an oligopolistic market.

The model has a conventional energy producer that acts as the follower and the leader is a renewable energy producer. Hence, we analyze the producers within a Stackelberg game. We use this game because renewable energy producers have contractual priority to produce and sell energy. ${ }^{1}$ Chang et al. (2013) also assume the same market structure in order to analyze the Taiwan market, although the analysis is only focused on a fixed-price FIT. In our analysis, renewable energy producers (i.e., the leaders) have a contractual

\footnotetext{
${ }^{1}$ We also analyzed two other market structures, namely a Cournot and a Stackelberg game assuming that the conventional energy producer is the leader and the renewable energy producer is the follower. The results for the three games are qualitatively the same for the timing and the value of the project. In other words, we draw the same conclusions regarding the timing of the investment and how the value of the project changes, despite the quantities produced in equilibrium are different.
} 
right to sell all the production output to the public electricity company (i.e., the follower) under the FIT contract. In addition, we include important managerial flexibilities with a real options model, such as information gathering and a waiting option to invest.

Assumption 1 The producers face the linear inverse demand function of the following form: ${ }^{2}$

$$
P\left(X_{t}, Q_{S}\right)=a X_{t}-b Q_{S}
$$

where $a>0, b>0 . X_{t}$ denotes the industry's demand shock at time $t$ observed by all firms, and $Q_{S}$ is the total output produced.

The subscript $S$ denotes the particular scheme we are considering. Regarding $S$, we denote the scenario without a FIT schemes (i.e. when the renewable energy producers do not have a FIT contract) with a subscript $W$, the scenario when the renewable energy producer has a minimum price guarantee contract with a subscript $M$, the scenario when renewable energy producer has a fixed-premium contract with a subscript $P$, and the scenario when renewable energy producer has a fixed-price contract with a subscript $F$. We assume that the conventional energy producer is active within the market and the renewable energy producer is waiting for the optimal time to invest.

Assumption 2 The industry demand shock $X_{t}$ follows the geometric Brownian motion process, under the risk neutral measure:

$$
d X_{t}=\mu X_{t} d t+\sigma X_{t} d W_{t}
$$

where $X_{0}=X>0, \mu<r$ is a deterministic risk-neutral drift, $r$ is the risk-free interest rate, $\sigma>0$ is the volatility, and $d W_{t}$ is the increment of a Wiener process.

Assumption 3 The profit function of the conventional energy producer is: ${ }^{3}$

$$
\Pi_{c S}\left(X_{t}\right)=P\left(X_{t}, Q_{S}\right) q_{c S}-C_{c S}
$$

where $q_{c S}$ is the quantity produced. The cost function has the following form $C_{c S}=k_{c} q_{c S}{ }^{\theta_{c}}$. In addition, the conventional energy producer has no capacity constraint.

Assumption 4 The four different profit functions of the renewable energy producer $\Pi_{r S}(X)$ that we analyze in this article are:

i) Scheme without FIT policy, for which $\Pi_{r W}\left(X_{t}\right)=P\left(X_{t}, Q_{S}\right) q_{r W}-C_{r W}$.

ii) Fixed-price scheme, for which $\Pi_{r F}\left(X_{t}\right)=F q_{r F}-C_{r F}$.

iii) Fixed-premium scheme, for which $\Pi_{r P}\left(X_{t}\right)=\left(P\left(X_{t}, Q_{S}\right)+F\right) q_{r P}-C_{r P}$.

iv) Minimum price guarantee scheme, for which $\Pi_{r M}\left(X_{t}\right)=\max \left[\Pi_{r F}\left(X_{t}\right), \Pi_{r W}\left(X_{t}\right)\right]$.

where the cost function of the renewable energy producer also has the form $C_{r S}=k_{r} q_{r S} \theta_{r}$, $F$ is the value of the tariff due to the FIT contract and $Q_{S}=q_{c S}+q_{r S}$. In addition, $q_{r S} \leqslant Q_{r}$, where $Q_{r}$ is the maximum output that can be generated. ${ }^{4}$

\footnotetext{
${ }^{2}$ Dangl (1999) uses the same inverse demand function to analyze a firm's installed capacity in a monopoly with a real options approach.

${ }^{3}$ We denote the conventional energy producer with a subscript $c$ and the renewable energy producer with a subscript $r$.

${ }^{4}$ We explain each one of these schemes in more details in the subsequent sections.
} 
We assume that the cost function of the conventional energy is different from the renewable energy. This is due to the fact that many renewable energy technologies have a marginal production cost equal to zero, according to the data from the US Energy Information Administration (EIA 2017). Hence $k_{r}<<k_{c}$, where $k_{r}$ is almost zero. In addition, we use the following assumptions in our model for the cost functions: (i) a linear cost function for the renewable energy producer, where $\theta_{r}=1$, because it is reasonable to assume that the marginal cost is constant for the renewable energy, and (ii) a quadratic cost function for the conventional energy producer, where $\theta_{c}=2$, because it is reasonable to assume that conventional energy has an increasing marginal cost. Twomey \& Neuhoff (2010) and Langary, Sadati \& Ranjbar (2014) also use a quadratic cost function in their models, which is the usual approximation for conventional energy cost. ${ }^{5}$

We also assume that renewable energy producer has a maximum output $\left(Q_{r}\right)$ that is limited by the capacity installed. For example, it is commonly assumed that wind farms produce at around $30 \%$ of the total capacity.

The remainder of this section presents the value of the active project and the value of the option to invest, which is used to derive the optimal investment thresholds in the following sections of this paper. We also present the social welfare analysis at the end of this section in order to compare the different FIT schemes and analyze the benefits the schemes may generate to the economy's overall sense of well-being.

\subsection{The value of firms}

In our setting the conventional energy producer is already active in the market and, therefore, its value is given by the revenue stream:

$$
V_{c S}(X)=\int_{0}^{+\infty} \Pi_{c S}\left(X_{t}\right) e^{-r t} d t
$$

The renewable energy producer can be either active or idle, waiting for the optimal investment timing. Let $V_{r S}(X(t))$ be the value of the active project. Upon investment, the value of the project is equal to the expected present value of the revenue stream. In addition, the value of the project with a FIT contract has a finite duration $T$. After time $T$, the renewable energy producer sells the energy for the market price $P$. Therefore, the value of the project $V_{r S}(X)$ upon investment is given by: ${ }^{6}$

$$
V_{r S}(X)=\int_{0}^{T} \Pi_{r S}\left(X_{t}\right) e^{-r t} d t+\int_{T}^{+\infty} \Pi_{r W}\left(X_{t}\right) e^{-r t} d t
$$

A renewable energy producer has a waiting option which is held until the stochastic revenue flow reaches a sufficiently high level at which it is optimal to exercise the investment option. The option to invest is exercised by paying a sunk cost $I$, which is the investment cost per unit of capacity. Let $F_{r S}(X)$ be the value of the investment option. Applying Itô's Lemma (Dixit \& Pindyck 1994) leads us to the Ordinary Differential Equation (ODE):

$$
0.5 \sigma^{2} X^{2} \frac{\partial^{2} F_{r S}(X)}{\partial X^{2}}+\mu X \frac{\partial F_{r S}(X)}{\partial X}-r F_{r S}(X)=0
$$

\footnotetext{
${ }^{5}$ We can also extend the model for other industries, and assume different values for $\theta$.

${ }^{6}$ We explain in more details how to calculate the value of the project in each one of the schemes in the subsequent sections.
} 
The general solution to this ODE is given by:

$$
F_{r S}(X)=A_{1} X^{\beta_{1}}+A_{2} X^{\beta_{2}}
$$

where $A_{1}$ and $A_{2}$ are constants determined by economic boundary conditions. In addition, $\beta_{1}\left(\beta_{2}\right)$ is the positive (negative) root of the following quadratic equation:

$$
\frac{1}{2} \sigma^{2} \beta(\beta-1)+\beta \mu-r=0
$$

Hence,

$$
\begin{aligned}
& \beta_{1}=\frac{1}{2}-\frac{\mu}{\sigma^{2}}+\left(\left(-\frac{1}{2}+\frac{\mu}{\sigma^{2}}\right)^{2}+\frac{2 r}{\sigma^{2}}\right)^{\frac{1}{2}}>1 \\
& \beta_{2}=\frac{1}{2}-\frac{\mu}{\sigma^{2}}-\left(\left(-\frac{1}{2}+\frac{\mu}{\sigma^{2}}\right)^{2}+\frac{2 r}{\sigma^{2}}\right)^{\frac{1}{2}}<0 .
\end{aligned}
$$

Assuming that the producer has a perpetual option to invest for a sunk cost $I$ per unit of capacity $Q_{r}$, we find the value of the investment option $F_{r S}(X)$ and the optimal investment trigger $X_{r S}^{*}$. As the function $F_{r S}(X)$ must be continuous and differentiable in all its domain, we apply the value matching and smooth pasting conditions. In addition, as $F_{r S}(0)=0$ (which implies that $A_{2}=0$ ), the value of the option to invest is given by:

$$
F_{r S}(X)= \begin{cases}A_{1} X^{\beta_{1}} & X<X_{r S}^{*} \\ V_{c S}(X)-I Q_{r} & X \geqslant X_{r S}^{*}\end{cases}
$$

where $A_{1}$ and $X_{r S}^{*}$ are such that $A_{1} X_{r S}^{*}{ }^{\beta_{1}}=V_{r S}\left(X_{r S}^{*}\right)-I Q_{r}$ and $\beta_{1} A_{1} X_{r S}^{*}{ }^{\beta_{1}-1}=\left.\frac{\partial V_{r S}(X)}{\partial X}\right|_{X=X_{r S}^{*}}$ (i.e., the value matching and smooth pasting conditions).

\subsection{Social welfare}

In order to compare the FIT schemes, we calculate the social welfare $W_{S}$ for three market scenarios where a policymaker offers a fixed-price FIT, fixed-premium FIT and a FIT with a minimum price guarantee. The aim is to compare these different policy schemes and how they can impact the economic welfare of a population. We also calculate the social welfare for a market scenario where a policymaker does not offer a FIT scheme (i.e., a free-market condition), which serves as a baseline for the policy schemes. The social welfare includes the consumers' surplus, the value of the project of the energy producers, an environmental damage, and the public expenditure due to the FIT schemes. Hence, the social welfare $W_{S}(X)$ is given by:

$$
W_{S}(X)=C S_{S}(X)+V_{c S}(X)+F_{r S}(X)-E D_{S}(X)-P E_{S}(X)
$$

where the first term represents the consumers' surplus, which is equal to $\frac{b}{2}\left[Q_{S}(X)\right]^{2}$ for the linear demand function; the second and third terms are the value of the firm that generates energy from conventional resources and the value of the option of the firm that generates energy from renewable resources respectively, $V_{c S}(X)+F_{r S}(X)$ (i.e., the producers' surplus); the fourth term is the environmental damage function, which is assumed to 
be equal to $K_{G}\left[q_{c S}\left(X_{t}\right)\right]^{2}$, where $K_{G}$ is the increment in marginal environmental damage due to the green house gas (GHG) emission; and the last term is the public expenditure due to the FIT schemes.

We consider that the value of public expenditure $P E_{S}(X)$ can assume three different values, depending on the FIT policy. First, the cost of the fixed-price FIT scheme is equal to the difference between the value of the tariff $F$ and the market price $P$ times $q_{r F}\left(X_{t}\right)$. The intuition behind this is that the regulator pays $F$ per unit of energy to the producer and sells it for $P$ to the market. Note that the fixed-price FIT scheme can generate a positive cash flow if the market price $P$ is greater than the tariff $F$. Second, the cost of the fixed-premium FIT is equal to $F$ times the energy produced $q_{r P}\left(X_{t}\right)$. Third, the cost of the FIT with a minimum price guarantee is equal to $F-P$ when $X$ is below a given threshold and zero otherwise, for every unit of energy.

In addition, we assume that the environmental damage function is convex. This function calculates the environmental damage when energy is produced by conventional resources (i.e., $\left.q_{c S}\left(X_{t}\right)\right)$ such as petroleum or coal. This function was also used by Chang et al. (2013).

The remainder of this section presents the results for the market scenarios and schemes that we address along the paper.

\subsection{Conventional energy producer monopoly}

We first calculate the social welfare for a monopoly, because we have to take into account that the market has only one conventional producer before the investment occurs. When the renewable energy producer exercises the investment option, the market will then become a duopoly (i.e.: the monopoly ends when $\mathrm{X}$ hits $X_{r S}^{*}$ ).

Hence, in this section, we analyze a scenario where there is only one conventional firm that sells energy for the market price and the renewable energy producer is still waiting to start the investment. We first derive the profit function of the conventional firm to find the quantity that maximizes the profit.

The following proposition characterizes the industry outputs given that the market is a monopoly: ${ }^{7}$

Proposition 1 The strategy of the conventional firm is to produce $q_{c Y}$, which is the quantity that maximizes the profit:

$$
q_{c Y}\left(X_{t}\right)=\frac{a}{2\left(b+k_{c}\right)} X_{t}
$$

Thus, $q_{c Y}$ generates the following profit:

$$
\Pi_{c Y}\left(X_{t}\right)=\frac{a^{2}}{4\left(b+k_{c}\right)} X_{t}^{2}
$$

Note that the profit function in Equation (12) is proportional to $X^{2}$. Hence, it is straightforward to prove by Itô's Lemma that the profit follows the following stochastic process:

$$
d \Pi_{c Y_{t}}=\left(2 \mu+\sigma^{2}\right) \Pi_{c Y_{t}} d t+2 \sigma \Pi_{c Y} d W_{t}
$$

Therefore, the appropriate discounted rate to find the value of the project is $r-\alpha$, where $\alpha=2 \mu+\sigma^{2}$.

\footnotetext{
${ }^{7}$ We denote a scenario with a monopoly with a subscript $Y$
} 
Proposition 2 The social welfare value $W_{Y}$ for a monopoly is:

$$
W_{Y}(X)=C S_{Y}(X)+V_{c Y}(X)-E D_{Y}(X)
$$

where $C S_{Y}(X)$ is the consumers' surplus:

$$
C S_{Y}(X)=\int_{0}^{+\infty} \frac{b}{2}\left[q_{c Y}\left(X_{t}\right)\right]^{2} e^{-r t} d t=\frac{b}{2} \frac{q_{c Y}^{2}}{(r-\alpha)}=\frac{a^{2} b}{8\left(b+k_{c}\right)^{2}} \frac{X^{2}}{(r-\alpha)}=h_{22} \frac{X^{2}}{r-\alpha}
$$

the value of the conventional firm $V_{c Y}(X)$ is:

$$
V_{c Y}(X)=\int_{0}^{+\infty} \Pi_{c Y}\left(X_{t}\right) e^{-r t} d t=\frac{a^{2}}{4\left(b+k_{c}\right)} \frac{X^{2}}{(r-\alpha)}=h_{32} \frac{X^{2}}{r-\alpha}
$$

and, the environmental damage $E D_{Y}(X)$ is:

$$
E D_{Y}(X)=\int_{0}^{+\infty} K_{G}\left[q_{c Y}\left(X_{t}\right)\right]^{2} e^{-r t} d t=K_{G} \frac{a^{2}}{4\left(b+k_{c}\right)^{2}} \frac{X^{2}}{(r-\alpha)}=K_{G} h_{42} \frac{X^{2}}{r-\alpha}
$$

\subsection{Conventional and renewable energy producers duopoly}

In this section, we analyze a scenario where the renewable energy producer has already entered the market, and thus derive the Stackelberg leadership game to find the market equilibrium.

In order to model the optimal output, we may find two market equilibria. In the first equilibrium the renewable energy firm produces at the maximum output $Q_{r}$, and in the second equilibrium the renewable energy firm produces below $Q_{r}$. For the sake of simplicity, we assume that the renewable energy firm produces always at full capacity. On the one hand, for very small marginal production costs the second equilibrium is almost unattainable, having a negligible impact in the results. ${ }^{8}$ On the other hand, the regulator may require that renewable energy firms produce at full capacity, for example for environmental reasons.

Assuming that the renewable energy producer produces always at full capacity, the output of both producers is invariant with the FIT Scheme. Being a function only of these quantities, the revenue flow of the conventional producer, the instantaneous consumers' surplus and the instantaneous environmental damage are also invariant with the FIT Scheme.

The following proposition presents the quantities of both the renewable energy firm and conventional energy firm in a Stackelberg equilibrium:

Proposition 3 The optimal strategy for the conventional energy firm is to produce $q_{c S}(X)$, which maximizes the profit:

$$
q_{c S}\left(X_{t}\right)=-\frac{b Q_{r}}{2\left(b+k_{c}\right)}+\frac{a}{2\left(b+k_{c}\right)} X_{t}, \quad S \in\{W, F, P, M\}
$$

Hence, the profit of the conventional energy firm is equal to $\Pi_{c S}(X)$ :

$$
\Pi_{c S}\left(X_{t}\right)=\frac{b^{2} Q_{r}^{2}}{4\left(b+k_{c}\right)}-\frac{a b Q_{r}}{2\left(b+k_{c}\right)} X_{t}+\frac{a^{2}}{4\left(b+k_{c}\right)} X_{t}^{2}=h_{30}+h_{31} X_{t}+h_{32} X_{t}^{2}
$$

${ }^{8}$ Barbosa (2019) provides the same results as in this article allowing for the two equilibria. Additionally, Twomey \& Neuhoff (2010) considers the renewable energy cost to be equal to zero. 
In order to calculate the social welfare $W_{S}(X)$, we present the values of the instantaneous consumers' surplus $\frac{b}{2}\left[Q_{S}\left(X_{t}\right)\right]^{2}$ and the term of the environmental damage $\left[q_{c S}\left(X_{t}\right)\right]^{2}$ :

$$
\begin{aligned}
\frac{b}{2}\left[Q_{S}\left(X_{t}\right)\right]^{2} & =\frac{\left(b^{2}+4 k_{c}\left(b+k_{c}\right)\right) b Q_{r}^{2}}{8\left(b+k_{c}\right)^{2}}+\frac{\left(b+2 k_{c}\right) a b Q_{r}}{4\left(b+k_{c}\right)^{2}} X_{t}+\frac{a^{2} b}{8\left(b+k_{c}\right)^{2}} X_{t}^{2} \\
& =h_{20}+h_{21} X+h_{22} X^{2} \\
{\left[q_{c S}\left(X_{t}\right)\right]^{2} } & =\frac{b^{2} Q_{r}^{2}}{4\left(b+k_{c}\right)^{2}}-\frac{a b Q_{r}}{2\left(b+k_{c}\right)^{2}} X_{t}+\frac{a^{2}}{4\left(b+k_{c}\right)^{2}} X_{t}^{2}=h_{40}+h_{41} X_{t}+h_{42} X_{t}^{2}
\end{aligned}
$$

The instantaneous revenue flow of the renewable energy producer depends on the FIT scheme, which in turn determines its investment timing. Therefore, the FIT schemes have different welfare effects but only as a result of the different entry timings of the renewable energy producer.

The following propositions calculate the terms of the social welfare, namely the consumers' surplus, the producers' surplus, and the environmental damage. We take into account that the market is a monopoly before investment occurs.

Proposition 4 The consumers' surplus $C S_{S}(X)$ is given by:

$$
C S_{S}\left(X, X_{r S}^{*}\right)=C S_{Y}(X)- \begin{cases}\left(C S_{Y}\left(X_{r S}^{*}\right)-C S_{S D}\left(X_{r S}^{*}\right)\right)\left(\frac{X}{X_{r S}^{*}}\right)^{\beta_{1}} & \text { for } X<X_{r S}^{*} \\ C S_{Y}(X)-C S_{S D}(X) & \text { for } X \geqslant X_{r S}^{*}\end{cases}
$$

where $C S_{Y}(X)$ is the consumers' surplus of a monopoly (Equation (15)) and $C S_{S D}(X)$ is the consumers' surplus in a duopoly. We calculate $C S_{S D}(X)$ as following:

$$
C S_{S D}(X)=\int_{0}^{+\infty} \frac{b}{2}\left[Q_{S}\left(X_{t}\right)\right]^{2} e^{-r t} d t=h_{20} \frac{1}{r}+h_{21} \frac{X}{r-\mu}+h_{22} \frac{X^{2}}{r-\alpha}
$$

For $X<X_{r S}^{*}$, note that the consumers' surplus $C S_{S}(X)$ is equal to the consumers' surplus of a monopoly that changes to a duopoly when $X$ hits $X_{r S}^{*}$. When $X \geqslant X_{r S}^{*}$, the consumers' surplus $C S_{S}(X)$ is equal to the consumers' surplus in a duopoly. The intuition behind the consumers' surplus $C S_{S}(X)$ in Equation (22) is that the market is a monopoly before the renewable energy firm exercises the option to invest. Consequently, the monopoly terminates when $X=X_{r S}^{*}$ and thus the market becomes a duopoly.

Next, we follow the same steps as above in order to calculate the value of the conventional firm $V_{c S}$, which is a component of the producers' surplus.

Proposition 5 The value of the conventional firm $V_{c S}(X)$ is:

$$
V_{c S}\left(X, X_{r S}^{*}\right)=V_{c Y}(X)- \begin{cases}\left(V_{c Y}\left(X_{r S}^{*}\right)-V_{c S D}\left(X_{r S}^{*}\right)\right)\left(\frac{X}{X_{r S}^{*}}\right)^{\beta_{1}} & \text { for } X<X_{r S}^{*} \\ V_{c Y}(X)-V_{c S D}(X) & \text { for } X \geqslant X_{r S}^{*}\end{cases}
$$

where $V_{c Y}(X)$ is the value of the conventional firm in a monopoly, which has been calculated in (16). In addition, the value of the conventional firm $V_{c S D}(X)$ in a duopoly is the following:

$$
V_{c S D}(X)=\int_{0}^{+\infty} \Pi_{c S}\left(X_{t}\right) e^{-r t} d t=h_{30} \frac{1}{r}+h_{31} \frac{X}{r-\mu}+h_{32} \frac{X^{2}}{r-\alpha}
$$


For $X<X_{r S}^{*}$, note that the value of the conventional firm $V_{c W}(X)$ (i.e., Equation $(24))$ is equal to the value of the conventional firm in a perpetual monopoly minus the loss in value when the renewable energy firm enters the market. When $X \geqslant X_{r S}^{*}$, the value of the conventional firm is equal to the value of the firm in a duopoly.

Next, we calculate the value of the environmental damage $E D_{S}$ :

Proposition 6 The environmental damage $E D_{S}(X)$ is:

$$
E D_{S}\left(X, X_{r S}^{*}\right)=E D_{Y}(X)- \begin{cases}\left(E D_{Y}\left(X_{r S}^{*}\right)-E D_{S D}\left(X_{r S}^{*}\right)\right)\left(\frac{X}{X_{r S}^{*}}\right)^{\beta_{1}} & \text { for } X<X_{r S}^{*} \\ E D_{Y}(X)-E D_{S D}(X) & \text { for } X \geqslant X_{r S}^{*}\end{cases}
$$

where $E D_{Y}(X)$ is the environmental damage in a monopoly (i.e., Equation (17)) and $E D_{S D}(X)$ is the environmental damage in a duopoly, which is given by:

$$
E D_{S D}(X)=\int_{0}^{+\infty} K_{G}\left[q_{c S}\left(X_{t}\right)\right]^{2} e^{-r t} d t=K_{G}\left(h_{40} \frac{1}{r}+h_{41} \frac{X}{r-\mu}+h_{42} \frac{X^{2}}{r-\alpha}\right)
$$

Note that, similarly to the consumers' surplus and the value of the conventional firm, the first branch of Equation (26) includes the value of the environmental damage when the renewable energy firm has the option to invest. Additionally, the second branch is equal to the environmental damage in a duopoly.

\subsubsection{Free-market scenario}

Now, we calculate the value of the project in a free-market scenario. Let $V_{r W}(X)$ denote the value of the project when the policymaker does not offer a FIT contract.

Proposition 7 The renewable energy firm, producing $q_{r}=Q_{r}$, has profit of:

$$
\Pi_{r W}\left(X_{t}\right)=\left(-k_{r}-\frac{b\left(b+2 k_{c}\right) Q_{r}}{2\left(b+k_{c}\right)}\right) Q_{r}+\frac{a\left(b+2 k_{c}\right) Q_{r}}{2\left(b+k_{c}\right)} X_{t}=h_{10}+h_{11} X_{t}
$$

The value of the renewable energy project without a FIT contract is given by:

$$
V_{r W}(X)=\int_{0}^{+\infty} \Pi_{r W}\left(X_{t}\right) e^{-r t} d t=h_{10} \frac{1}{r}+h_{11} \frac{X}{r-\mu}
$$

Now, we follow the steps in Section 3.1 in order to obtain the value of the option to invest and value of the investment trigger for a scenario without a FIT scheme:

Proposition 8 The value of the option to invest is given by:

$$
F_{r W}(X)=\left\{\begin{array}{lr}
\left(V_{r W}\left(X_{r W}^{*}\right)-I Q_{r}\right)\left(\frac{X}{X_{r W}^{*}}\right)^{\beta_{1}} & \text { for } X<X_{r W}^{*} \\
V_{r W}(X)-I Q_{r} & \text { for } X \geqslant X_{r W}^{*}
\end{array}\right.
$$

where the investment threshold $X_{r W}^{*}$ is:

$$
X_{r W}^{*}=\frac{\beta_{1}}{\beta_{1}-1}\left(\frac{r-\mu}{h_{11}}\right)\left(I Q_{r}-\frac{h_{10}}{r}\right)
$$


Equation (32) presents the value of the social welfare $W_{W}(X)$ when the renewable energy producer does not have a FIT contract:

$$
W_{W}(X)=C S_{W}(X)+V_{c W}(X)+F_{r W}(X)-E D_{W}(X)
$$

The social welfare in Equation (32) has three main components, namely the consumers' surplus, the producers' surplus and the environmental damage. Given that no FIT is offered, there is no pubic expenditure. The consumers' surplus $C S_{W}(X)=$ $C S_{S}\left(X, X_{r W}^{*}\right)$ is in Equation (22). The producers' surplus is equal to the value conventional firm and the option to invest (i.e., $V_{c W}(X)=V_{c S}\left(X, X_{r W}^{*}\right)+F_{r W}(X)$ ), where $V_{c W}(X)$ is in Equation (24) and $F_{r W}(X)$ is in Equation (30). The environmental damage $E D_{W}(X)=E D_{S}\left(X, X_{r W}^{*}\right)$ is in Equation (26).

\subsubsection{Fixed-price FIT}

In this scenario, the renewable energy producer has a fixed-price FIT contract with a finite duration, where the firm receives $F$ for a period of time $T$. Among all FIT designs, the fixed-price FIT is the most widely used FIT scheme around the world. For instance, fixed-price FIT policies have been offered in Germany, France, Portugal, Canada, and many other countries. ${ }^{9}$

Following the same steps of the previous section, let $V_{r F}(X)$ be the value of the project when the renewable energy producer has a fixed-price contract with a finite duration $T$. After time $T$, the renewable energy producer sells the energy for the market price $P$.

Proposition 9 The value of the project at the time of the investment is:

$$
\begin{aligned}
V_{r F}(X) & =\int_{0}^{T}\left(F-k_{r}\right) Q_{r} e^{-r t} d t+\int_{T}^{+\infty} \Pi_{r W}\left(X_{t}\right) e^{-r t} d t \\
& =\frac{\left(F-k_{r}\right) Q_{r}}{r}\left(1-e^{-r T}\right)+h_{10} \frac{1}{r} e^{-r T}+h_{11} \frac{X}{r-\mu} e^{-(r-\mu) T}
\end{aligned}
$$

Note that the first integral is the profit when the producer has a fixed-price contract. The second integral is the profit after the FIT contract has expired.

Following the steps in Section 3.1, we have the following proposition:

Proposition 10 The value of the option to invest is given by:

$$
F_{r F}(X)=\left\{\begin{array}{lr}
\left(V_{r F}\left(X_{r F}^{*}\right)-I Q_{r}\right)\left(\frac{X}{X_{r F}^{*}}\right)^{\beta_{1}} & \text { for } X<X_{r F}^{*} \\
V_{r F}(X)-I Q_{r} & \text { for } X \geqslant X_{r F}^{*}
\end{array}\right.
$$

where the investment threshold $X_{r F}^{*}$ is:

$$
X_{r F}^{*}=\frac{\beta_{1}}{\beta_{1}-1}\left(\frac{r-\mu}{h_{11} e^{-(r-\mu) T}}\right)\left(I Q_{r}-\frac{\left(F-k_{r}\right) Q_{r}\left(1-e^{-r T}\right)+h_{10} e^{-r T}}{r}\right)
$$

\footnotetext{
${ }^{9}$ Under fixed-price FIT the renewable energy firm always produces the maximum output $Q_{r}$, because the maximum output $Q_{r}$ maximizes the profit of a producer with a fixed-price FIT. In other words, even if we relax the assumption, a renewable energy firm with a fixed-price FIT always produces as much as possible in order to maximize its profit.
} 
When the renewable energy firm receives a fixed amount $F$ and produces the maximum output $Q_{r}$, the following proposition states the value of the public expenditure:

Proposition 11 When the renewable energy firm produces $q_{r F}=Q_{r}$ and receives a fixedprice FIT, the instantaneous public expenditure is:

$$
(F-P) Q_{r}=\left(\frac{b\left(b+2 k_{c}\right) Q_{r}}{2\left(b+k_{c}\right)}+F\right) Q_{r}-\frac{a\left(b+2 k_{c}\right) Q_{r}}{2\left(b+k_{c}\right)} X=\left(F-k_{r}\right) Q_{r}-h_{10}-h_{11} X
$$

The value of the public expenditure of a fixed-price FIT contract at the time of the investment is:

$$
\begin{aligned}
E_{F}(X)=\int_{0}^{T}\left(\left(F-k_{r}\right)\right. & \left.Q_{r}-h_{10}-h_{11} X\right) e^{-r t} d t \\
= & \left(\left(F-k_{r}\right) Q_{r}-h_{10}\right) \frac{\left(1-e^{-r T}\right)}{r}-h_{11} \frac{X}{r-\mu}\left(1-e^{-(r-\mu) T}\right)
\end{aligned}
$$

Note that the public expenditure has the same duration $T$ of the FIT contract.

In addition, the present value of the public expenditure of a fixed-price FIT contract is:

$$
P E_{F}(X)= \begin{cases}E_{F}\left(X_{r F}^{*}\right)\left(\frac{X}{X_{r F}^{*}}\right)^{\beta_{1}} & \text { for } X<X_{r F}^{*} \\ E_{F}(X) & \text { for } X \geqslant X_{r F}^{*}\end{cases}
$$

Hence, the value of the social welfare is:

$$
W_{F}(X)=C S_{F}(X)+V_{c F}(X)+F_{r F}(X)-E D_{F}(X)-P E_{F}(X)
$$

where $C S_{F}(X)=C S_{S}\left(X, X_{r F}^{*}\right)$ is in Equation $(22), V_{c F}(X)=V_{c S}\left(X, X_{r F}^{*}\right)$ is in Equation (24), $F_{r F}(X)$ is in Equation (34), $E D_{F}(X)=E D_{S}\left(X, X_{r F}^{*}\right)$ is in Equation (26), and $P E_{F}(X)$ is in Equation (38).

\subsubsection{Fixed-premium FIT}

In this section, we analyze a fixed-premium contract within an oligopolistic market. In this policy, the firm receives a fixed bonus $F$ over the market price. Fixed-premium FITs have been offered in countries such as Spain, Czech Republic, and the Netherlands.

Following the same steps of the previous sections, we derive the value of the project $V_{r P}(X)$ when the firm has a fixed-premium contract with a finite duration. ${ }^{10}$

Proposition 12 The renewable energy firm, producing $q_{r}=Q_{r}$, has profit the following profit when receiving a fixed-premium FIT:

$$
\Pi_{r F}\left(X_{t}\right)=\left(F-k_{r}-\frac{b\left(b+2 k_{c}\right) Q_{r}}{2\left(b+k_{c}\right)}\right) Q_{r}+\frac{a\left(b+2 k_{c}\right) Q_{r}}{2\left(b+k_{c}\right)} X_{t}=F Q_{r}+h_{10}+h_{11} X_{t}
$$

\footnotetext{
${ }^{10}$ It is possible to show that, even if allowed to produce below the maximum output, the renewable energy firm with a fixed-premium contract always produces the maximum output, if $Q_{r}$ is not very large (Barbosa 2019).
} 
The value of the project at the time of the investment is:

$$
\begin{aligned}
V_{r P}(X) & =\int_{0}^{T} \Pi_{r F}\left(X_{t}\right) e^{-r t} d t+\int_{T}^{+\infty} \Pi_{r W}\left(X_{t}\right) e^{-r t} d t \\
& =\frac{F Q_{r}}{r}\left(1-e^{-r T}\right)+h_{10} \frac{1}{r}+h_{11} \frac{X}{r-\mu}
\end{aligned}
$$

Following the steps in Section 3.1, we have the following Propositions:

Proposition 13 The value of the option to invest is given by:

$$
F_{r P}(X)=\left\{\begin{array}{lr}
\left(V_{r P}\left(X_{r P}^{*}\right)-I Q_{r}\right)\left(\frac{X}{X_{r P}^{*}}\right)^{\beta_{1}} & \text { for } X<X_{r P}^{*} \\
V_{r P}(X)-I Q_{r} & \text { for } X \geqslant X_{r P}^{*}
\end{array}\right.
$$

where the investment threshold $X_{r P}^{*}$ is:

$$
X_{r P}^{*}=\frac{\beta_{1}}{\beta_{1}-1}\left(\frac{r-\mu}{h_{11}}\right)\left(I Q_{r}-\frac{F Q_{r}\left(1-e^{-r T}\right)+h_{10}}{r}\right)
$$

The next proposition presents the public expenditure of having a scheme with a fixedpremium FIT, $P E_{P}(X)$. Recall that the instantaneous public expenditure is equal to $F Q_{r}$.

Proposition 14 The public expenditure $P E_{P}(X)$ is given by:

$$
P E_{P}(X)= \begin{cases}F Q_{r}\left(\frac{1-e^{-r T}}{r}\right)\left(\frac{X}{X_{r P}^{*}}\right)^{\beta_{1}} & \text { for } X<X_{r P}^{*} \\ F Q_{r}\left(\frac{1-e^{-r T}}{r}\right) & \text { for } X \geqslant X_{r P}^{*}\end{cases}
$$

Therefore, the value of the social welfare with a fixed-premium policy is the following:

$$
W_{P}(X)=C S_{P}(X)+V_{c P}(X)+F_{r P}(X)-E D_{P}(X)-P E_{P}(X)
$$

where $C S_{P}(X)=C S_{S}\left(X, X_{r P}^{*}\right)$ is in Equation $(22), V_{c P}(X)=V_{c S}\left(X, X_{r P}^{*}\right)$ is in Equation (24), $F_{r P}(X)$ is in Equation (42), $E D_{P}(X)=E D_{S}\left(X, X_{r P}^{*}\right)$ is in Equation (26), and $P E_{P}(X)$ is in Equation (44).

\subsubsection{FIT with a minimum price guarantee}

A FIT with a minimum price guarantee is a price-floor regime, whereby a producer receives a fixed amount $F$ per unit of energy when the profit flow for selling energy to the market is lower than the profit generated with the price floor. On the other hand, the producer sells energy for the market price when the profit flow for selling energy to the market is above the profit from the price floor. Netherlands, Ireland and Switzerland are examples of jurisdictions that have used variations of the price-floor regime in a FIT contract. 
The renewable energy producer maximizes its profit by choosing an appropriate quantity that depends on $X_{t}$. In other words, an $X_{t}$ above a value leads to the equilibrium where producers sells energy at the market price. An $X_{t}$ below this same value takes the producer to the equilibrium where the producer receives a fixed amount $F{ }^{11}$

Proposition 15 When renewable energy firm receives the fixed amount $F$, it has the following profit flow:

$$
\Pi_{r M 1}=\left(F-k_{r}\right) Q_{r},
$$

and when selling at the market price, it has the following profit:

$$
\Pi_{r M 2}\left(X_{t}\right)=\Pi_{r W}\left(X_{t}\right)
$$

where $\Pi_{r W}\left(X_{t}\right)$ is given by Equation (28).

Now, let us denote $X_{F}$ the value of the demand shock where the profit generated by the fixed amount (i.e., Equation (46)) is equal to the profit when the firm sells energy to the market and produces the maximum output (i.e., Equation (47)). Hence, the value of $X_{F}$ is given by:

$$
X_{F}=\frac{b}{a} Q_{r}+\frac{2\left(b+k_{c}\right)}{a\left(b+2 k_{c}\right)} F=\left(\frac{b}{a}+\frac{F}{h_{11}}\right) Q_{r}
$$

Now, we build on the work from Barbosa et al. (2018) in order to find the value of project, the value of the option, and the investment trigger.

Proposition 16 The value of the project with a finite minimum price guarantee contract at the time of the investment is given by: ${ }^{12}$

$$
\begin{aligned}
V_{r M}(X)=V_{M}^{P}(X)-S(X)+ & \int_{T}^{+\infty} \Pi_{r W}\left(X_{t}\right) e^{-r t} d t \\
& =V_{M}^{P}(X)-S(X)+h_{10} \frac{1}{r} e^{-r T}+h_{11} \frac{X}{r-\mu} e^{-(r-\mu) T}
\end{aligned}
$$

where $V_{M}^{P}$ is the value of the project with a perpetual minimum price guarantee contract, and $S(X)$ is a forward-start perpetual minimum price guarantee.

The value of the project with a perpetual minimum price guarantee is:

$$
V_{M}^{P}(X)= \begin{cases}G_{11} X^{\beta_{1}}+\left(F-k_{r}\right) Q_{r} \frac{1}{r} & \text { for } X<X_{F} \\ H_{12} X^{\beta_{2}}+h_{10} \frac{1}{r}+h_{11} \frac{X}{r-\mu} & \text { for } X \geqslant X_{F}\end{cases}
$$

where $G_{11}$ and $H_{12}$ are calculated by equating the values and the derivatives in the two branches of Equation (50), which yields:

$$
\begin{aligned}
& G_{11}=\frac{X_{F}^{-\beta_{1}}}{\beta_{1}-\beta_{2}}\left(\frac{\beta_{2}\left(\left(F-k_{r}\right) Q_{r}-h_{10}\right)}{r}-\frac{\left(\beta_{2}-1\right) h_{11} X_{F}}{r-\mu}\right) \\
& H_{12}=\frac{X_{F}^{-\beta_{2}}}{\beta_{1}-\beta_{2}}\left(\frac{\beta_{1}\left(\left(F-k_{r}\right) Q_{r}-h_{10}\right)}{r}-\frac{\left(\beta_{1}-1\right) h_{11} X_{F}}{r-\mu}\right)
\end{aligned}
$$

\footnotetext{
${ }^{11}$ It is possible to show that, allowing for the firm to produce below maximum output, the firm will produce always at maximum output when facing a demand with low elasticity (Barbosa 2019).

${ }^{12}$ For more details see the work from Barbosa et al. (2018).
} 
The forward-start perpetual minimum price guarantee $S(X)$ is given by:

$$
\begin{aligned}
S(X)=G_{11} X^{\beta_{1}}(1- & \left.N\left(d_{\beta_{1}}\right)\right)+\left(F-k_{r}\right) Q_{r} \frac{1}{r} e^{-r T}\left(1-N\left(d_{0}\right)\right) \\
& +H_{12} X^{\beta_{2}} N\left(d_{\beta_{2}}\right)+h_{10} \frac{1}{r} e^{-r T} N\left(d_{0}\right)+h_{11} \frac{X}{r-\mu} e^{-(r-\mu) T} N\left(d_{1}\right)
\end{aligned}
$$

where, $N($.$) is the cumulative normal integral and$

$$
d_{\beta}=\frac{\ln \frac{X}{X_{F}}+\left(\mu+\sigma^{2}\left(\beta-\frac{1}{2}\right)\right) T}{\sigma \sqrt{T}}
$$

Following the steps in Section 3.1, we now calculate the value of the option to invest and the investment trigger.

Proposition 17 The value of the option to invest is given by:

$$
F_{r M}(X)=\left\{\begin{array}{lr}
\left(V_{r M}\left(X_{r M}^{*}\right)-I Q_{r}\right)\left(\frac{X}{X_{r M}^{*}}\right)^{\beta_{1}} & \text { for } X<X_{r M}^{*} \\
V_{r M}(X)-I Q_{r} & \text { for } X \geqslant X_{r M}^{*}
\end{array}\right.
$$

where the investment threshold $X_{r M}^{*}$ for the first branch of Equation (50) (i.e.: $X_{r M}^{*}<$ $\left.X_{F}\right)$ is the solution of the following equation that must be solved numerically:

$$
\begin{aligned}
& \left(\beta_{1}-\beta_{2}\right) H_{12} X_{r M}^{*_{2}} N\left(d_{\beta_{2}}\right)-\left(\beta_{1}-1\right) h_{11} \frac{X_{r M}^{*}}{r-\mu} e^{-(r-\mu) T}\left(1-N\left(d_{1}\right)\right) \\
& \quad+\beta_{1}\left(I Q_{r}-\frac{\left(F-k_{r}\right) Q_{r}+\left(\left(F-k_{r}\right) Q_{r}-h_{10}\right) e^{-r T}\left(1-N\left(d_{0}\right)\right)}{r}\right)=0
\end{aligned}
$$

and the investment threshold $X_{r M}^{*}$ for the second branch of Equation (50) (i.e.: $X_{r M}^{*} \geqslant$ $\left.X_{F}\right)$ is the solution of the following equation that must be solved numerically:

$$
\begin{aligned}
\left(\beta_{1}-\beta_{2}\right) H_{12} X_{r M}^{*_{2}}\left(1-N\left(d_{\beta_{2}}\right)\right)+\left(\beta_{1}-1\right) h_{11} \frac{X_{r M}^{*}}{r-\mu}\left(1+e^{-(r-\mu) T}\left(1-N\left(d_{1}\right)\right)\right) \\
-\beta_{1}\left(I Q_{r}-\frac{h_{10}-\left(\left(F-k_{r}\right) Q_{r}-h_{10}\right) e^{-r T}\left(1-N\left(d_{0}\right)\right)}{r}\right)=0
\end{aligned}
$$

Now we calculate the public expenditure of the FIT with a minimum price guarantee, $P E_{M}(X)$. Note that the public expenditure when $X<X_{F}$ is the same as the public expenditure with a fixed amount (i.e., Equation (36)). When $X \geqslant X_{F}$, the public expenditure is zero because the producer sells energy to the market.

Proposition 18 The public expenditure of a minimum price guarantee policy is given by:

$$
P E_{M}(X)= \begin{cases}E_{M}\left(X_{r M}^{*}\right)\left(\frac{X}{X_{r M}^{*}}\right)^{\beta_{1}} & \text { for } X<X_{r M}^{*} \\ E_{M}(X) & \text { for } X \geqslant X_{r M}^{*}\end{cases}
$$




$$
E_{M}(X)=P E_{M}^{P}(X)-S_{M}(X)
$$

where $P E_{M}^{P}(X)$ is a perpetual public expenditure of a minimum price guarantee policy, and $S_{M}(X)$ is a forward-start public expenditure of a minimum price guarantee policy that starts at time $T$. Therefore, we have the followings:

$$
P E_{M}^{P}(X)= \begin{cases}G_{21} X^{\beta_{1}}+\left(\left(F-k_{r}\right) Q_{r}-h_{10}\right) \frac{1}{r}-h_{11} \frac{X}{r-\mu} & \text { for } X<X_{F} \\ H_{22} X^{\beta_{2}} & \text { for } X \geqslant X_{F}\end{cases}
$$

$G_{11}$ and $H_{12}$ are calculated by equating the values and the derivatives in the two branches of Equation (60), which yields:

$$
\begin{aligned}
& G_{21}=\frac{X_{F}^{-\beta_{1}}}{\beta_{1}-\beta_{2}}\left(\frac{\beta_{2}\left(\left(F-k_{r}\right) Q_{r}-h_{10}\right)}{r}-\frac{\left(\beta_{2}-1\right) h_{11} X_{F}}{r-\mu}\right)=G_{11} \\
& H_{22}=\frac{X_{F}^{-\beta_{2}}}{\beta_{1}-\beta_{2}}\left(\frac{\beta_{1}\left(\left(F-k_{r}\right) Q_{r}-h_{10}\right)}{r}-\frac{\left(\beta_{1}-1\right) h_{11} X_{F}}{r-\mu}\right)=H_{12}
\end{aligned}
$$

Following the steps in Barbosa et al. (2018), $S_{M}(X)$, is given by:

$$
\begin{aligned}
S_{M}(X)=G_{11} & X^{\beta_{1}}\left(1-N\left(d_{\beta_{1}}\right)\right)+H_{12} X^{\beta_{2}} N\left(d_{\beta_{2}}\right) \\
& +\left(\left(F-k_{r}\right) Q_{r}-h_{10}\right) \frac{1}{r} e^{-r T}\left(1-N\left(d_{0}\right)\right)-h_{11} \frac{X}{r-\mu} e^{-(r-\mu) T} N\left(d_{1}\right)
\end{aligned}
$$

where $N($.$) is given in Equation (54).$

Hence, the value of the social welfare with a finite minimum price guarantee scheme is given by:

$$
W_{M}(X)=C S_{M}(X)+V_{c M}(X)+F_{r M}(X)-E D_{M}(X)-P E_{M}(X)
$$

where $C S_{M}(X)=C S_{S}\left(X, X_{r M}^{*}\right)$ is in Equation $(22), V_{c M}(X)=V_{c S}\left(X, X_{r M}^{*}\right)$ is in Equation $(24), F_{r M}(X)$ is in Equation $(55), E D_{M}(X)=E D_{S}\left(X, X_{r M}^{*}\right)$ is in Equation (26), and $P E_{M}(X)$ is in Equation (58).

\section{Designing optimal FIT schemes}

From a policymaking perspective, an optimal FIT scheme should be designed to maximize the incremental welfare. In our setting, where the renewable energy producer always produces at maximum capacity, the effect of the FIT schemes on the social welfare is driven only by the investment timing, whereby a new firm enters the market and changes the market equilibrium, increasing competition. Therefore, it is expected that a scheme than induces investment timing to be that which maximizes the welfare value, is an optimally designed scheme.

The following proposition presents the welfare increment produced by the introduction of a FIT scheme with a given tariff $F$ and duration $T$. 
Proposition 19 The incremental welfare value of introducing a FIT scheme $S \in\{F, P, M\}$ is:

$$
\begin{aligned}
\Delta W_{S}(X)= & W_{S}(X)-W_{W}(X) \\
= & \begin{cases}\left(h_{0} \frac{1}{r}+h_{1} \frac{X_{r S}^{*}}{r-\mu}-I Q_{r}\right)\left(\frac{X}{X_{r S}^{*}}\right)^{\beta_{1}} \\
\quad-\left(h_{0} \frac{1}{r}+h_{1} \frac{X_{r W}^{*}}{r-\mu}-I Q_{r}\right)\left(\frac{X}{X_{r W}^{*}}\right)^{\beta_{1}} & \text { for } X<X_{r S}^{*}<X_{r W}^{*} \\
0 & \text { for } X \geqslant X_{r S}^{*}\end{cases}
\end{aligned}
$$

where

$$
\begin{aligned}
& h_{0}=h_{10}+h_{20}+h_{30}-K_{G} h_{40} \\
& h_{1}=h_{11}+h_{21}+h_{31}-K_{G} h_{41}
\end{aligned}
$$

Proof. See Appendix.

The constants $h_{0}$ and $h_{1}$ aggregate the incremental impact of a FIT scheme on (i) the renewable energy producer surplus and public expenditure $\left(h_{10}\right.$ and $\left.h_{11}\right)$, (ii) the consumer surplus $\left(h_{20}\right.$ and $h_{21}$ ), (iii) the conventional energy producer surplus $\left(h_{30}\right.$ and $\left.h_{41}\right)$, (iv) and the environmental damage $\left(h_{40}\right.$ and $\left.h_{31}\right)$. By introducing a FIT scheme, a Government transfers value directly, through cash payments, to the renewable energy producer, and affects indirectly, through the investment timing, the surplus of the conventional energy producer, the consumers' surplus and the environmental damage. Because the firms' output is independent of the FIT scheme, the incremental welfare is null after the renewable energy producer enters the market $\left(X \geqslant X_{r S}^{*}\right)$. Before that, the incremental welfare is the difference between the incremental welfare arising from competition due the different entry timings of the new firm when offered a FIT incentive $\left(X_{r S}^{*}\right)$ and in its absence $\left(X_{r W}^{*}\right)$.

An optimal feed-in tariff, $F_{S}^{*}$, maximizes the welfare value, solving the following optimization problem: ${ }^{13}$

$$
W_{S}^{*}(X)=\max _{F} \Delta W_{S}(X)=\max _{F}\left(h_{0} \frac{1}{r}+h_{1} \frac{X_{r S}^{*}}{r-\mu}-I Q_{r}\right)\left(\frac{X}{X_{r S}^{*}}\right)^{\beta_{1}}
$$

Given that in Equation (65) only $X_{r S}^{*}$ is a function of $F$, this optimization problem is equivalent to:

$$
W_{S}^{*}(X)=\max _{X_{r S}^{*}} \Delta W_{S}(X)=\max _{X_{r S}^{*}}\left(h_{0} \frac{1}{r}+h_{1} \frac{X_{r S}^{*}}{r-\mu}-I Q_{r}\right)\left(\frac{X}{X_{r S}^{*}}\right)^{\beta_{1}}
$$

which is exactly the same optimization problem that a central planner would solve to find the optimal investment timing of the renewable energy producer. The solution of (67) is stated in the following proposition:

Proposition 20 An optimally designed FIT scheme induces the renewable energy producer to invest when $X$ hits the following trigger:

$$
X_{r S}^{*}=\frac{\beta_{1}}{\beta_{1}-1}\left(\frac{r-\mu}{h_{1}}\right)\left(I Q_{r}-\frac{h_{0}}{r}\right)=X_{r}^{*}
$$

\footnotetext{
${ }^{13}$ Notice that in Equation $(65) h_{0}, h_{1}$, and $X_{r W}^{*}$ are not a function of $F$.
} 
which is the same for all schemes and produces the following maximum incremental welfare:

$$
W_{S}^{*}(X)=\frac{1}{\beta_{1}-1}\left(I Q_{r}-\frac{h_{0}}{r}\right)\left(\frac{X}{X_{r}^{*}}\right)^{\beta_{1}}-\frac{\beta_{1}\left(h_{1}-h_{11}\right)+h_{11}}{\left(\beta_{1}-1\right) h_{11}}\left(I Q_{r}-\frac{h_{0}}{r}\right)\left(\frac{X}{X_{r W}^{*}}\right)^{\beta_{1}}
$$

In order to induce the optimal behavior of the renewable energy producer, the FITs for the fixed and premium schemes are:

$$
\begin{aligned}
& F_{F}^{*}=\frac{e^{r T}}{Q_{r}\left(1-e^{r T}\right)}\left(e^{-(r-\mu) T} \frac{h_{11}}{h_{1}}\left(\frac{h_{0}}{r}-I Q_{r}\right)-e^{-r T} \frac{h_{10}}{r}-I Q_{r}\right)+k_{r} \\
& F_{P}^{*}=\frac{e^{r T}}{Q_{r}\left(1-e^{r T}\right)}\left(\frac{h_{11}}{h_{1}}\left(\frac{h_{0}}{r}-I Q_{r}\right)-\frac{h_{10}}{r}-I Q_{r}\right)
\end{aligned}
$$

and the optimal FIT for the floor scheme is found solving numerically for $F$ equations (56) or (57) substituting $X_{r}^{*}$ for $X_{r M}^{*}$.

An important implication of Proposition 20 is that the duration of the FIT scheme $(T)$ does not change the maximum attainable welfare (both $X_{r}^{*}$ and $X_{r M}^{*}$ are not a function of $T$ ), determining only the optimal FIT that should be offered. Other parameters can produce non-monotonic effects, since they impact both the timing of investment $\left(X_{r}^{*}\right.$ and $\left.X_{r M}^{*}\right)$ and the welfare payoffs (e.g. through $h_{0}, h_{1}$, and $h_{11}$ ).

\section{Comparative statics}

In this section, we present a comparative statics analysis of the main drivers of the option to invest and its threshold and the welfare value for the three FIT schemes, namely fixed price, fixed premium and minimum price guarantee. The base-case parameter values are presented in Table 1.

Accordingly with the assumptions in the previous sections, we set $\theta_{c}=2$. Hence, the marginal cost of the conventional firm increases as the production increases (i.e., increasing the quantity of energy produced makes the marginal cost more expensive). The reason for this assumption is that resources to produce energy become more expensive as the conventional firm produces more. For example, Twomey \& Neuhoff (2010) also assume that the cost function is quadratic for a conventional firm. We assume $k_{r}$ much smaller than $k_{c}$ and $\theta_{r}=1$, because the marginal cost of many renewable energy technologies are close to zero. The investments cost is the cost of a $2 \mathrm{MW}(€ 3,000,000)$ wind turbine per MWh of output, with a maximum output of $30 \%$ of the capacity installed. ${ }^{14}$ In addition, we assume $a=80$, and $b$ is set to produce reasonable output quantities for the two producers. ${ }^{15}$

\subsection{Investment timing under different FIT schemes}

Figure 1 shows that the investment triggers for the three FIT policies decrease as the tariff $F$ increases. In other words, the decision to invest accelerates when the tariff $F$ increases.

\footnotetext{
${ }^{14}$ The yearly output is $5,256 \mathrm{MWh}$.

${ }^{15}$ For $b=3$ and $X_{t}=1$, when the renewable energy producer output is $0.6 \mathrm{MW}$, the conventional energy producer output is $7.75 \mathrm{MW}$
} 
Table 1: Base-case parameters used to calculate the threshold

\begin{tabular}{ll}
\hline \hline$k_{c}$ & 2 \\
$k_{r}$ & 0.01 \\
$\theta_{c}$ & 2 \\
$\theta_{r}$ & 1 \\
$a$ & 80 \\
$b$ & 3 \\
$F$ & $€ 25 / \mathrm{MWh}$ \\
$T$ & 15 years \\
$I$ & $€ 570.776 / \mathrm{MWh}$ \\
$Q_{r}$ & $0.6 \mathrm{MW}$ \\
$r$ & 0.05 \\
$\mu$ & 0.00 \\
$\sigma$ & 0.2 \\
\hline \hline
\end{tabular}

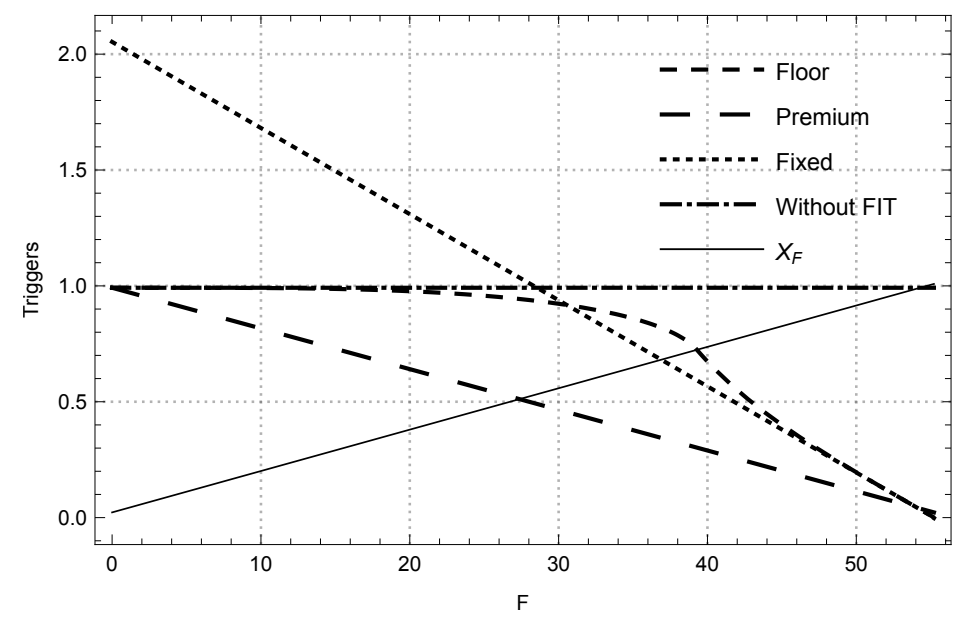

Figure 1: Investment triggers as a function of $F$

The trigger of the price-floor regime (i.e., FIT with a minimum price guarantee) converges to the trigger of the fixed-premium regime when the tariff $F$ goes to zero. In particular, both triggers have the same value when $F=0$, because the producer sells energy for the market price in both cases. In contrast, as the value of the tariff $F$ increases, a producer with a price-floor regime is more likely to sell energy for the tariff $F$ instead of the market price. Hence, the investment threshold of the price-floor regime converges to the fixed-price FIT. In addition, the triggers of the price-floor regime and fixed-premium FIT are always below the trigger without FIT scheme. However, the trigger with a fixed-price scheme is only below the trigger in a free-market scenario after the tariff $F$ is approximately $€ 29 / \mathrm{MWh}$. Hence, policymakers should only offer tariffs for fixed-price policy above this value. This happens because for values of the tariff below this amount it is more profitable to sell energy for the market price than to receive the fixed-price tariff. However, a producer with a fixed-price FIT contract does not have this option.

Figure $2 \mathrm{a}$ shows that the triggers of fixed-premium FIT and price-floor regime decrease as the duration of the contract $T$ increases. Producers with a fixed-premium FIT accelerate investment because they receive the bonus over the market price for a longer 


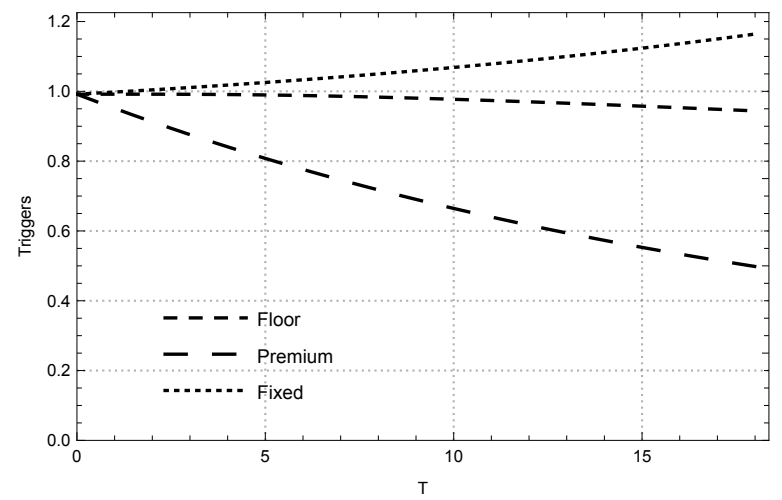

(a) $F=€ 25 / \mathrm{MWh}$

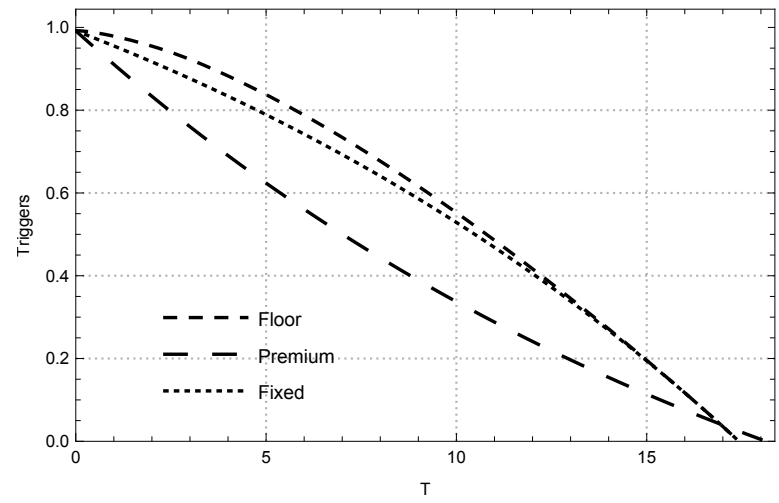

(b) $F=€ 50 / \mathrm{MWh}$

Figure 2: Investment triggers as a function of $T$

duration and thus increases the value of project. Producers with a price-floor regime accelerate investment because they have a guarantee for a longer period of time which reduces the risk of the investment. However, the behavior of the fixed-price trigger depends on the value of the tariff $F$. In Figure 2a, we observe the fixed-price trigger increases as $T$ increases when the tariff has a low value (i.e., $F=€ 25 / \mathrm{MWh}$ ). In contrast, Figure $2 \mathrm{~b}$ shows that the fixed-price trigger decreases as $T$ increases for higher values of the tariff (i.e., $€ 50 / \mathrm{MWh}$ ). Hence, policymakers should not offer low values of the tariff within a fixed-price FIT contract, because it will postpone investment.

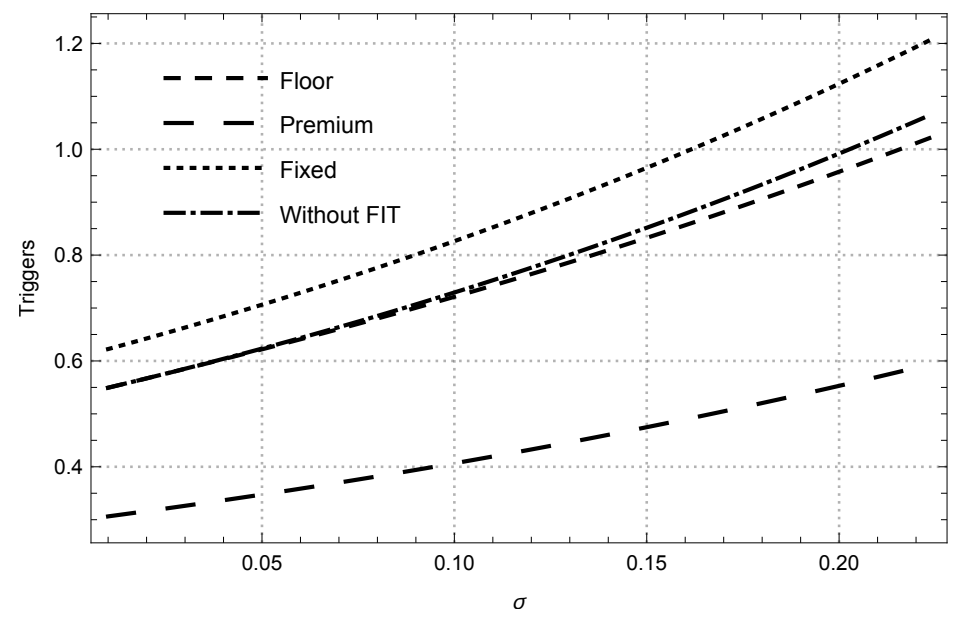

Figure 3: Investment triggers as a function of $\sigma$

Figure 3 illustrates that the investment thresholds increase as $\sigma$ increases. These results are consistent with the real options theory, whereby the effect of uncertainty accelerates the decision to invest. Next, we analyze a comparative statics analysis of the social welfare for the three FIT policies.

\subsection{The impact of FIT schemes on social welfare}

In this section, we present a comparative statics analysis, whereby we analyze the difference between the social welfare with a FIT policy and a social welfare without a FIT scheme. The social welfare without a FIT scheme assumes that the market has a renewable energy producer without a FIT contract. The aim is to analyze the inclusion of a 
FIT policy in a market without any support scheme and how the FIT policy increases or decrease the social welfare. We use the same base-case parameters in Table 1 together with $X=0.25$. In addition, we analyze a scenario where the environmental damage is low (i.e.: $K_{G}=5$ ) and another scenario where the environmental damage is high (i.e.: $\left.K_{G}=10\right)$.

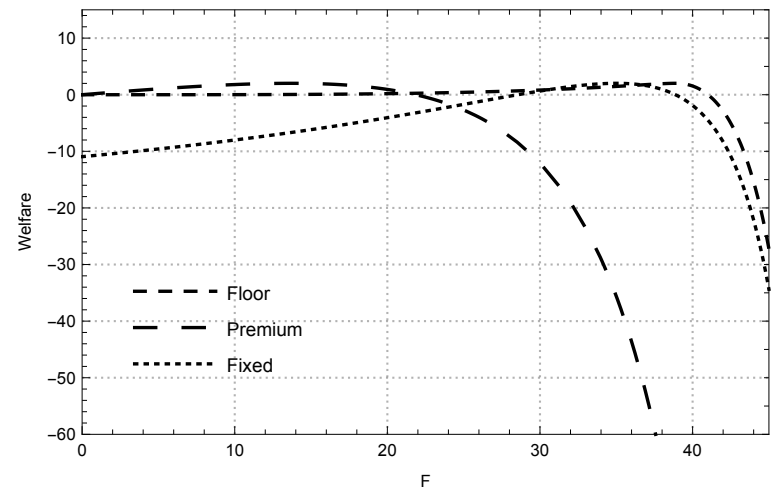

(a) $K_{G}=5$

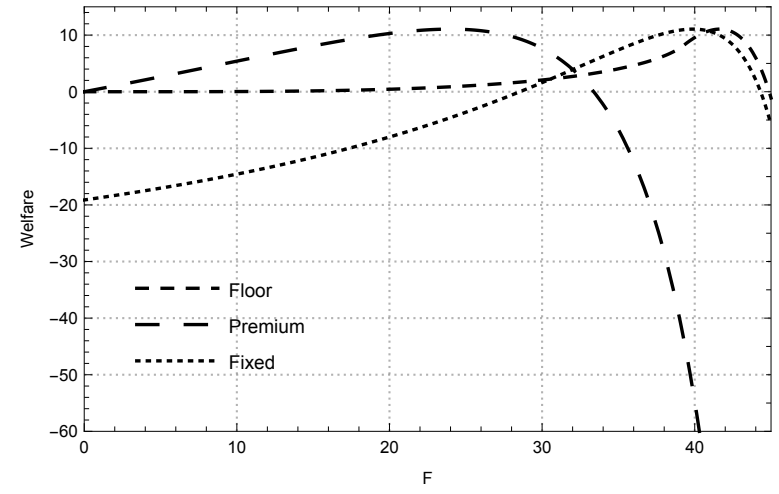

(b) $K_{G}=10$

Figure 4: Incremental social welfare as a function of the tariff $F$ for different values of the environmental damage

Figure 4a presents the incremental social welfare as a function of the tariff $F$, i.e. the difference between the social welfare of each FIT scheme and the free-market scenario. The marginal environmental damage $K_{G}$ is set equal to 5 . Note that the values of the incremental social welfare are either slightly positive or negative. A negative incremental social welfare means that the social welfare of a free-market scenario is higher than the social welfare of a scenario with a FIT scheme. When incremental social welfare is equal to zero, we have a scenario where it is indifferent for a policymaker to offer a FIT scheme or to let renewable energy producers sell energy to the market. A low $K_{G}$ applies to a jurisdiction where the population is not very concerned with the environmental damage of the the green house gas (GHG) emission.

In Figure $4 \mathrm{~b}$, we observe a different pattern, because the marginal environmental damage $K_{G}$ is set equal to 10 . A higher $K_{G}$ means that the population is more concerned regarding the green house gas (GHG) emission, which is due to the conventional firm's energy production. The plots in Figure $4 \mathrm{~b}$ present a maximum point for all three FIT schemes, where all maximum points are clearly positive. The values of the tariff that generate the maximum values of the incremental social welfare are approximately $€ 22$ / MWh for the fixed-premium FIT, $€ 40$ for the fixed-price FIT, and $€ 41$ for the price-floor regime. The values of the tariff that maximize the incremental social welfare represent a scenario where the inclusion of FIT policies generate a higher social welfare than the social welfare of the market without an support schemes. In addition, these values are the recommended tariffs for policymakers, because they maximize the social welfare of the population.

\subsection{Optimal FIT schemes}

Figure 5a presents the plots of the optimal FIT values as a function of the volatility. We can see that the optimal FIT values for the fixed price and fixed premium do not change when the volatility increases. The reason for this observation is that these optimal tariffs 
do not depend on the volatility, as shown in Equations 70 and 71 . However, the same does not occur with the price floor, whereby the optimal tariff now depends on the volatility. In other words, the optimal FIT for the price floor scheme is found solving equations (56) or (57) numerically, and these equations depend on the volatility. The economic intuition behind this effect is that the policymaker always pays the same tariff for the fixed price and fixed premium schemes regardless of the market price movement. However, this does not happen with the minimum price guarantee because a policymaker can either pay $F$ or the producer sells energy for the market price.

Figure 5b presents the plot of the investment trigger for the optimal designed FIT, which is the same for all the three schemes and compares it with the free-market scenario trigger. We observe that the trigger increases as the volatility value increases, which is consistent with the real options theory. In other words, investors postpone the investment decision when the volatility increases. Additionally, optimal FITs induce earlier investments when introduced. In Figure 5c, the plot shows the incremental welfare of the optimally designed FITs as a function of the volatility. The non-monotonic effect suggested before is show in the plot: the social welfare initially increases with the volatility and then starts decreasing.

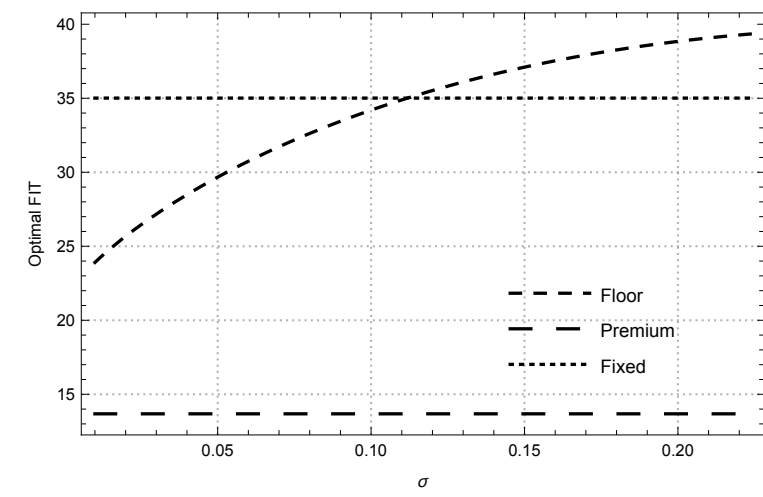

(a) Optimal FIT

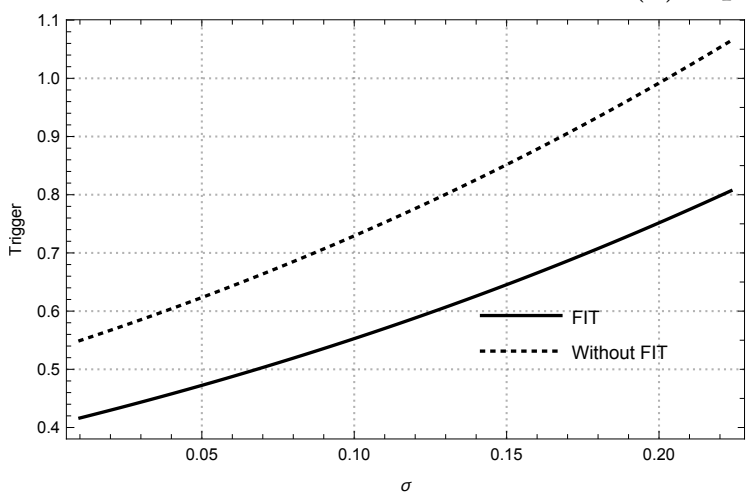

(b) Investment trigger

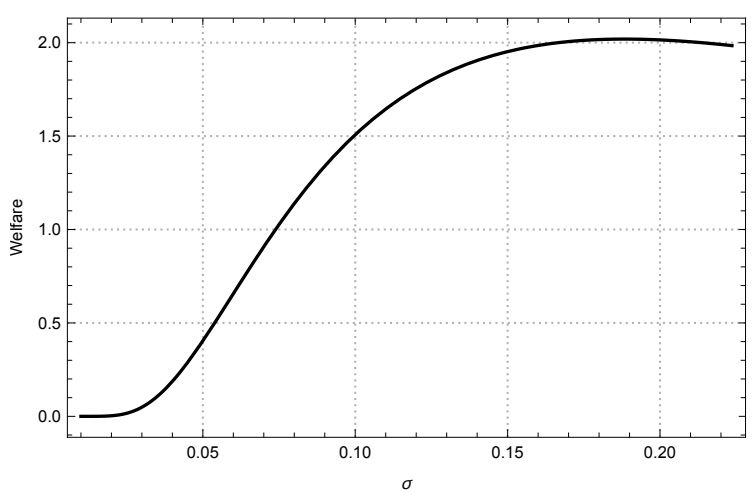

(c) Incremental social welfare

Figure 5: Maximum social welfare for different volatilities, $\sigma$

Figure 6a shows the optimal FIT values for different demand elasticities. Note that $b$ values close to zero represents a market condition with a highly elastic demand, while large $b$ values correspond to inelastic demand. A market with inelastic products, such as energy, represents a condition where consumers are not very sensitive to prices; hence, even if price increases, the consumption does not significantly change. Therefore, producers can increase price without affecting the demand. In contrast, for highly elastic products, 
consumers are very sensitive to prices. The results show that the curve is non-monotonic because for very small values of $b$ the optimal FIT increases and rapidly starts decreasing. Hence, as the market presents a more inelastic demand, the optimal tariffs decrease. Note that the optimal market dependent FITs (premium and minimum price guarantee) are more sensitive to demand elasticity than the market independent scheme (fixed price).

In Figure 6b, we can see that the investment trigger is higher for an inelastic demand. Moreover, the investment trigger has a non-monotonic effect and the lowest trigger is more towards the elastic products, but cannot be completely elastic. A similar non-monotonic effect occurs for the social welfare (Figure 6c).

These results suggest that in markets with more inelastic demand functions, such as the energy markets, the social welfare is maximized with smaller values of the FIT tariffs, leading to later investment timings and smaller increments in the social welfare.

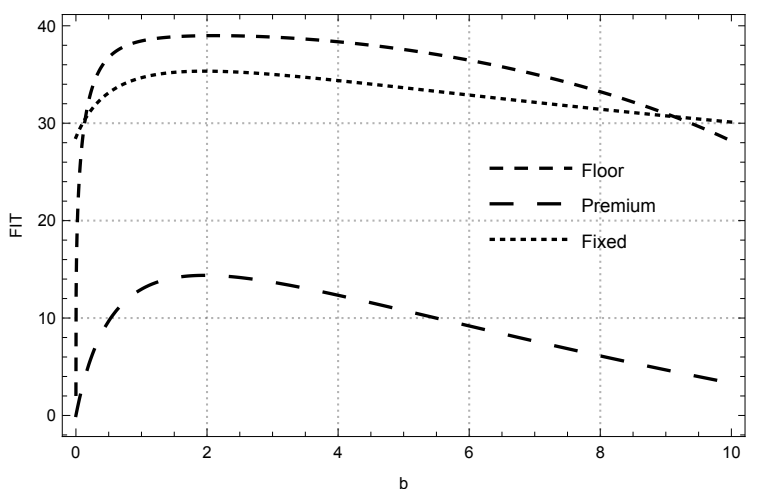

(a) Optimal FIT

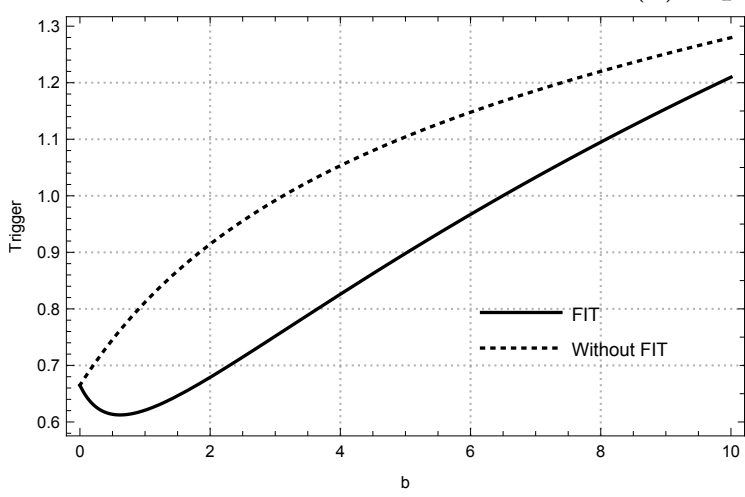

(b) Investment trigger

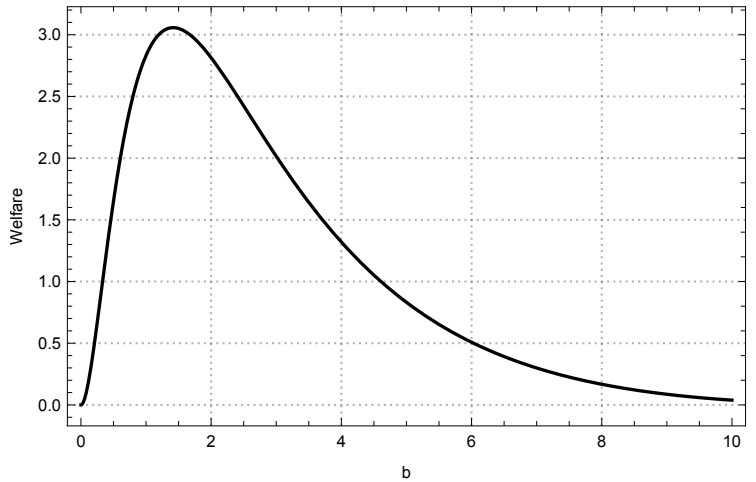

(c) Incremental social welfare

Figure 6: Maximum social welfare for different demand elasticities, $b$.

As previously suggested, the environmental damage is an important driver of the social welfare effects of the introducing of a FIT scheme. Figure 7 confirms that suggestion, showing that, when an optimal FIT tariff is used, a higher environmental induces earlier investments (7b) and higher social welfare increments (Figure 7c).

\section{Concluding remarks}

This work analyzes three different FIT schemes within an oligopolistic market structure, namely the fixed price, the fixed premium and the minimum price guarantee policies. In this analysis, we use an asymmetric Stackelberg model and a real options valuation 


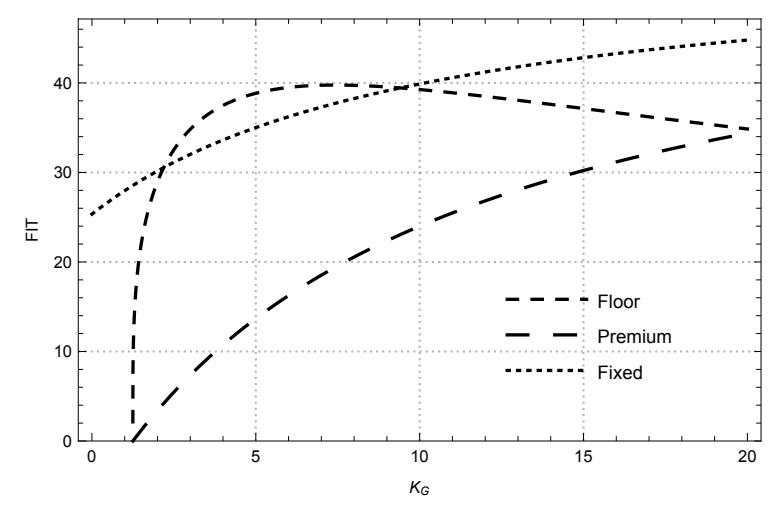

(a) Optimal FIT

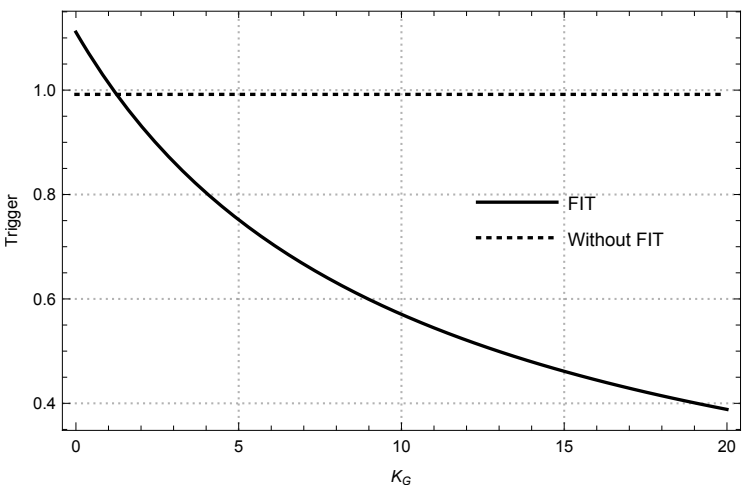

(b) Investment trigger

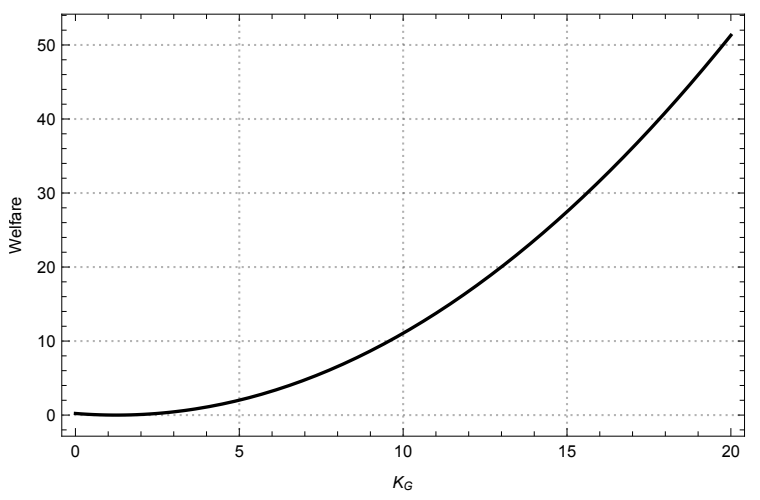

(c) Incremental social welfare

Figure 7: Maximum social welfare for different environmental damages, $K_{G}$

model. Not only does our model value investments in renewable energy projects from the perspective of a private investor but also a policymaking perspective. In particular, our model provides interesting insights to FIT design, where it can be used to provide recommendations for market design, including how to create appropriate investment incentives. In particular, the model presents the investment threshold and the value of the tariff $F$ that maximize the social welfare in the different types of FIT designs.

The key results of this paper are twofold. First, we identify the optimal time to deploy a renewable energy project. Second, we compare the three FIT contracts concerning the investment threshold and social welfare, to shed some light on the effectiveness of the three policy schemes. Besides, we analyze how the value and duration of a minimum price guarantee, a fixed premium and a fixed price affect the investment threshold and the social welfare.

The results show that the investment decision is accelerated for the three FIT schemes when the value of the tariff $F$ increases. Also, the investment thresholds of the fixedpremium FIT and the price-floor regime always decrease as the duration of the contract $T$ increases. However, the investment threshold of the fixed-price scheme decreases as $T$ increases for only higher values of the tariff. Hence, policymakers should not offer values of the tariff within a fixed-price FIT contract that postpone investment.

Regarding the social welfare, lower values of marginal environmental damage create a scenario where the FIT policies reduce or have a null impact at the most on the social welfare. This result may explain why many jurisdictions are reducing or even eliminating many FIT programs because lower values of the marginal environmental damage mean that society is not very concerned with the effects on the environment. In contrast, 
increasing the cost of environmental damage leads to positive effects of FIT policies on the social welfare.

Regarding the optimal FIT design, that maximizes the social welfare, a key result is that the optimal tariffs generate the same investment trigger and, therefore, the same increment in the social welfare. The duration of the FIT scheme does not change the maximum attainable welfare. We show that other parameters, such as market uncertainty and demand elasticity can produce non-monotonic effects. Finally, our results suggest that in markets with more inelastic demand functions, like the energy markets, an optimal designed FIT is smaller, inducing later investment and smaller increments in the social welfare.

\section{Acknowledgements}

This work was supported by a PhD scholarship provided by Fundação para a Ciência e a Tecnologia (FCT) through the MIT Portugal program under project SFRH/BD/52086/2013, and was supported by national funds through Fundação para a Ciência e a Tecnologia (FCT) with references UID/CEC/50021/2019 and UID/ECO/03182/2019. 


\section{Proof of Proposition 19.}

We first calculate the incremental social welfare of a fixed-price FIT scheme $\Delta W_{F}(X)=$ $W_{S}(X)-W_{W}(X)$.

From Equation (39), the social welfare with a fixed-price scheme is:

$$
W_{F}(X)=C S_{F}(X)+V_{c F}(X)+F_{r F}(X)-E D_{F}(X)-P E_{F}(X)
$$

Substituting Equation (22) for $C S_{F}(X)$, Equation (24) for $V_{c F}(X)$, Equation (34) for $F_{r F}(X)$, Equation (26) for $E D_{F}(X)$, and Equation (38) for $P E_{F}(X)$ in Equation (72) yields:

For $X<X_{r F}^{*}$

$$
\begin{gathered}
W_{F}(X)=h_{22} \frac{X^{2}}{r-\alpha}-\left(h_{22} \frac{X_{r F}^{*^{2}}}{r-\alpha}-\left(h_{20} \frac{1}{r}+h_{21} \frac{X_{r F}^{*}}{r-\mu}+h_{22} \frac{X_{r F}^{*^{2}}}{r-\alpha}\right)\right)\left(\frac{X}{X_{r F}^{*}}\right)^{\beta_{1}} \\
+h_{32} \frac{X^{2}}{r-\alpha}-\left(h_{32} \frac{X_{r F}^{*^{2}}}{r-\alpha}-\left(h_{30} \frac{1}{r}+h_{31} \frac{X_{r F}^{*}}{r-\mu}+h_{32} \frac{X_{r F}^{*^{2}}}{r-\alpha}\right)\right)\left(\frac{X}{X_{r F}^{*}}\right)^{\beta_{1}} \\
+\left(\frac{\left(F-k_{r}\right) Q_{r}}{r}\left(1-e^{-r T}\right)+\frac{h_{10}}{r} e^{-r T}+\frac{h_{11} X_{r F}^{*}}{r-\mu} e^{-(r-\mu) T}-I Q_{r}\right)\left(\frac{X}{X_{r F}^{*}}\right)^{\beta_{1}} \\
-\left(K_{G} h_{42} \frac{X^{2}}{r-\alpha}-\left(K_{G} h_{42} \frac{X_{r F}^{*^{2}}}{r-\alpha}-K_{G}\left(h_{40} \frac{1}{r}+h_{41} \frac{X_{r F}^{*}}{r-\mu}+h_{42} \frac{X_{r F}^{*^{2}}}{r-\alpha}\right)\right)\left(\frac{X}{X_{r F}^{*}}\right)^{\beta_{1}}\right) \\
-\left(\left(\left(F-k_{r}\right) Q_{r}-h_{10}\right) \frac{\left(1-e^{-r T}\right)}{r}-h_{11} \frac{X_{r F}^{*}}{r-\mu}\left(1-e^{-(r-\mu) T}\right)\right)\left(\frac{X}{X_{r F}^{*}}\right)^{\beta_{1}}
\end{gathered}
$$

Simplifying Equation (73) yields:

$$
\begin{aligned}
W_{F}(X)=h_{22} \frac{X^{2}}{r-\alpha}+ & \left(h_{20} \frac{1}{r}+h_{21} \frac{X_{r F}^{*}}{r-\mu}\right)\left(\frac{X}{X_{r F}^{*}}\right)^{\beta_{1}} \\
+ & h_{32} \frac{X^{2}}{r-\alpha}+\left(h_{30} \frac{1}{r}+h_{31} \frac{X_{r F}^{*}}{r-\mu}\right)\left(\frac{X}{X_{r F}^{*}}\right)^{\beta_{1}} \\
& +\left(h_{10} \frac{1}{r}+h_{11} \frac{X_{r F}^{*}}{r-\mu}-I Q_{r}\right)\left(\frac{X}{X_{r F}^{*}}\right)^{\beta_{1}} \\
- & K_{G} h_{42} \frac{X^{2}}{r-\alpha}-K_{G}\left(h_{40} \frac{1}{r}+h_{41} \frac{X_{r F}^{*}}{r-\mu}\right)\left(\frac{X}{X_{r F}^{*}}\right)^{\beta_{1}}
\end{aligned}
$$

In addition, from Equation (32), the social welfare with a free-market scenario is:

$$
W_{W}(X)=C S_{W}(X)+V_{c W}(X)+F_{r W}(X)-E D_{W}(X)
$$

Substituting Equation (22) for $C S_{W}(X)$, Equation (24) for $V_{c W}(X)$, Equation (30) 
for $F_{r W}(X)$ and Equation (26) for $E D_{W}(X)=E D_{S}\left(X, X_{r W}^{*}\right)$ yields:

$$
\begin{gathered}
W_{W}(X)=h_{22} \frac{X^{2}}{r-\alpha}-\left(h_{22} \frac{X_{r W}^{*^{2}}}{r-\alpha}-\left(h_{20} \frac{1}{r}+h_{21} \frac{X_{r W}^{*}}{r-\mu}+h_{22} \frac{X_{r W}^{*^{2}}}{r-\alpha}\right)\right)\left(\frac{X}{X_{r W}^{*}}\right)^{\beta_{1}} \\
+h_{32} \frac{X^{2}}{r-\alpha}-\left(h_{32} \frac{X_{r W}^{*^{2}}}{r-\alpha}-\left(h_{30} \frac{1}{r}+h_{31} \frac{X_{r W}^{*}}{r-\mu}+h_{32} \frac{X_{r W}^{*^{2}}}{r-\alpha}\right)\right)\left(\frac{X}{X_{r W}^{*}}\right)^{\beta_{1}} \\
+\left(h_{10} \frac{1}{r}+h_{11} \frac{X_{r W}^{*}}{r-\mu}-I Q_{r}\right)\left(\frac{X}{X_{r W}^{*}}\right)^{\beta_{1}} \\
-K_{G} h_{42} \frac{X^{2}}{r-\alpha}+\left(K_{G} h_{42} \frac{X_{r W}^{*^{2}}}{r-\alpha}-K_{G}\left(h_{40} \frac{1}{r}+h_{41} \frac{X_{r W}^{*}}{r-\mu}+h_{42} \frac{X_{r W}^{*^{2}}}{r-\alpha}\right)\right)\left(\frac{X}{X_{r W}^{*}}\right)^{\beta_{1}}
\end{gathered}
$$

Simplifying Equation (76) yields:

$$
\begin{aligned}
W_{W}(X)=h_{22} \frac{X^{2}}{r-\alpha}+ & \left(h_{20} \frac{1}{r}+h_{21} \frac{X_{r W}^{*}}{r-\mu}\right)\left(\frac{X}{X_{r W}^{*}}\right)^{\beta_{1}} \\
+ & h_{32} \frac{X^{2}}{r-\alpha}+\left(h_{30} \frac{1}{r}+h_{31} \frac{X_{r W}^{*}}{r-\mu}\right)\left(\frac{X}{X_{r W}^{*}}\right)^{\beta_{1}} \\
& +\left(h_{10} \frac{1}{r}+h_{11} \frac{X_{r W}^{*}}{r-\mu}-I Q_{r}\right)\left(\frac{X}{X_{r W}^{*}}\right)^{\beta_{1}} \\
& \quad-K_{G} h_{42} \frac{X^{2}}{r-\alpha}-K_{G}\left(h_{40} \frac{1}{r}+h_{41} \frac{X_{r W}^{*}}{r-\mu}\right)\left(\frac{X}{X_{r W}^{*}}\right)^{\beta_{1}}
\end{aligned}
$$

Subtracting Equation (74) from Equation (77) yields:

$$
\begin{gathered}
\Delta W_{F}(X)=W_{F}(X)-W_{W}(X)=\left(h_{20} \frac{1}{r}+h_{21} \frac{X_{r F}^{*}}{r-\mu}\right)\left(\frac{X}{X_{r F}^{*}}\right)^{\beta_{1}}+\left(h_{30} \frac{1}{r}+h_{31} \frac{X_{r F}^{*}}{r-\mu}\right)\left(\frac{X}{X_{r F}^{*}}\right)^{\beta_{1}} \\
-K_{G}\left(h_{40} \frac{1}{r}+h_{41} \frac{X_{r F}^{*}}{r-\mu}\right)\left(\frac{X}{X_{r F}^{*}}\right)^{\beta_{1}}+\left(h_{10} \frac{1}{r}+h_{11} \frac{X_{r F}^{*}}{r-\mu}-I Q_{r}\right)\left(\frac{X}{X_{r F}^{*}}\right)^{\beta_{1}} \\
-\left(h_{20} \frac{1}{r}+h_{21} \frac{X_{r W}^{*}}{r-\mu}\right)\left(\frac{X}{X_{r W}^{*}}\right)^{\beta_{1}}-\left(h_{30} \frac{1}{r}+h_{31} \frac{X_{r W}^{*}}{r-\mu}\right)\left(\frac{X}{X_{r W}^{*}}\right)^{\beta_{1}} \\
-\left(h_{10} \frac{1}{r}+h_{11} \frac{X_{r W}^{*}}{r-\mu}-I Q_{r}\right)\left(\frac{X}{X_{r W}^{*}}\right)^{\beta_{1}}+K_{G}\left(h_{40} \frac{1}{r}+h_{41} \frac{X_{r W}^{*}}{r-\mu}\right)\left(\frac{X}{X_{r W}^{*}}\right)^{\beta_{1}}
\end{gathered}
$$

Substituting $h_{0}$ for $h_{10}+h_{20}+h_{30}-K_{G} h_{40}$ and $h_{1}$ for $h_{11}+h_{21}+h_{31}-K_{G} h_{41}$ yields:

$$
\begin{aligned}
\Delta W_{F}(X)=W_{F}(X)-W_{W}(X)=\left(h_{0} \frac{1}{r}+\right. & \left.h_{1} \frac{X_{r F}^{*}}{r-\mu}-I Q_{r}\right)\left(\frac{X}{X_{r F}^{*}}\right)^{\beta_{1}} \\
& -\left(h_{0} \frac{1}{r}+h_{1} \frac{X_{r W}^{*}}{r-\mu}-I Q_{r}\right)\left(\frac{X}{X_{r W}^{*}}\right)^{\beta_{1}}
\end{aligned}
$$

For $X \geqslant X_{r F}^{*}$ 
Following the same steps

$$
\begin{aligned}
W_{F}(X)=h_{22} \frac{X^{2}}{r-\alpha}-\left(h_{20} \frac{1}{r}+h_{21} \frac{X}{r-\mu}+h_{22} \frac{X^{2}}{r-\alpha}\right) \\
\quad+h_{32} \frac{X^{2}}{r-\alpha}-\left(h_{30} \frac{1}{r}+h_{31} \frac{X}{r-\mu}+h_{32} \frac{X^{2}}{r-\alpha}\right) \\
+\frac{\left(F-k_{r}\right) Q_{r}}{r}\left(1-e^{-r T}\right)+\frac{h_{10}}{r} e^{-r T}+\frac{h_{11} X}{r-\mu} e^{-(r-\mu) T}-I Q_{r} \\
-\left(K_{G} h_{42} \frac{X^{2}}{r-\alpha}-K_{G}\left(h_{40} \frac{1}{r}+h_{41} \frac{X}{r-\mu}+h_{42} \frac{X^{2}}{r-\alpha}\right)\right) \\
\quad-\left(\left(F-k_{r}\right) Q_{r}-h_{10}\right) \frac{\left(1-e^{-r T}\right)}{r}+h_{11} \frac{X_{r F}^{*}}{r-\mu}\left(1-e^{-(r-\mu) T}\right)
\end{aligned}
$$

Simplifying Equation (80) yields:

$$
\begin{aligned}
W_{F}(X)=h_{22} \frac{X^{2}}{r-\alpha} & -\left(h_{20} \frac{1}{r}+h_{21} \frac{X}{r-\mu}+h_{22} \frac{X^{2}}{r-\alpha}\right) \\
+ & h_{32} \frac{X^{2}}{r-\alpha}-\left(h_{30} \frac{1}{r}+h_{31} \frac{X}{r-\mu}+h_{32} \frac{X^{2}}{r-\alpha}\right) \\
& \quad h_{10} \frac{1}{r}+h_{11} \frac{X}{r-\mu}-I Q_{r}+K_{G}\left(h_{40} \frac{1}{r}+h_{41} \frac{X}{r-\mu}\right)
\end{aligned}
$$

In addition, the social welfare with a free-market scenario for $X \geqslant X_{r F}^{*}$ is:

$$
\begin{aligned}
W_{W}(X)=h_{22} \frac{X^{2}}{r-\alpha} & -\left(h_{20} \frac{1}{r}+h_{21} \frac{X}{r-\mu}+h_{22} \frac{X^{2}}{r-\alpha}\right) \\
+ & h_{32} \frac{X^{2}}{r-\alpha}-\left(h_{30} \frac{1}{r}+h_{31} \frac{X}{r-\mu}+h_{32} \frac{X^{2}}{r-\alpha}\right) \\
& +h_{10} \frac{1}{r}+h_{11} \frac{X}{r-\mu}-I Q_{r}+K_{G}\left(h_{40} \frac{1}{r}+h_{41} \frac{X}{r-\mu}\right)
\end{aligned}
$$

It is straightforward to see that subtracting Equation (81) from Equation (82) yields zero. Hence, the incremental welfare for the fixed-price scheme is:

$$
\begin{aligned}
\Delta W_{F}(X)= & W_{F}(X)-W_{W}(X) \\
& = \begin{cases}\left(h_{0} \frac{1}{r}+h_{1} \frac{X_{r F}^{*}}{r-\mu}-I Q_{r}\right)\left(\frac{X}{X_{r F}^{*}}\right)^{\beta_{1}} \\
-\left(h_{0} \frac{1}{r}+h_{1} \frac{X_{r W}^{*}}{r-\mu}-I Q_{r}\right)\left(\frac{X}{X_{r W}^{*}}\right)^{\beta_{1}} & \text { for } X<X_{r F}^{*} \\
0 & \text { for } X \geqslant X_{r F}^{*}\end{cases}
\end{aligned}
$$

where

$$
\begin{aligned}
& h_{0}=h_{10}+h_{20}+h_{30}-K_{G} h_{40} \\
& h_{1}=h_{11}+h_{21}+h_{31}-K_{G} h_{41}
\end{aligned}
$$


Following the same steps to find the incremental welfares for the fixed premium and minimum price guarantee schemes, it is straightforward to see that the only difference among all FITs schemes is the investment timing.

Hence, the incremental welfare value of introducing a FIT scheme $S \in\{F, P, M\}$ is:

$$
\begin{aligned}
\Delta W_{S}(X)= & W_{S}(X)-W_{W}(X) \\
& = \begin{cases}\left(h_{0} \frac{1}{r}+h_{1} \frac{X_{r S}^{*}}{r-\mu}-I Q_{r}\right)\left(\frac{X}{X_{r S}^{*}}\right)^{\beta_{1}} \\
\quad-\left(h_{0} \frac{1}{r}+h_{1} \frac{X_{r W}^{*}}{r-\mu}-I Q_{r}\right)\left(\frac{X}{X_{r W}^{*}}\right)^{\beta_{1}} & \text { for } X<X_{r S}^{*}<X_{r W}^{*} \\
0 & \text { for } X \geqslant X_{r S}^{*}\end{cases}
\end{aligned}
$$

where

$$
\begin{aligned}
& h_{0}=h_{10}+h_{20}+h_{30}-K_{G} h_{40} \\
& h_{1}=h_{11}+h_{21}+h_{31}-K_{G} h_{41}
\end{aligned}
$$




\section{References}

Abadie, Luis M. \& José M. Chamorro (2014), 'Valuation of wind energy projects: A real options approach', Energies 7(5), 3218-3255.

Barbosa, Luciana, Paulo Ferrão, Artur Rodrigues \& Alberto Sardinha (2018), 'Feed-in tariffs with minimum price guarantees and regulatory uncertainty', Energy Economics 72, 517-541.

Barbosa, Luciana Salles (2019), Managerial Flexibilities and Regulatory Uncertainty in Feed-In Tariffs, PhD thesis, PhD Degree in Sustainable Energy Systems, University of Lisbon.

Boomsma, Trine Krogh, Nigel Meade \& Stein-Erik Fleten (2012), 'Renewable energy investments under different support schemes: A real options approach', European Journal of Operational Research 220(1), 225 - 237.

Ceseña, E.A. Martínez, J. Mutale \& F. Rivas-Dávalos (2013), 'Real options theory applied to electricity generation projects: A review', Renewable and Sustainable Energy Reviews 19, 573 - 581 .

Chang, Ming-Chung, Jin-Li Hu \& Tsung-Fu Han (2013), 'An analysis of a feed-in tariff in taiwan's electricity market', Electrical Power and Energy Systems 44, 916-920.

Chuang, A.S., F. Wu \& P. Varaiya (2001), 'A game-theoretic model for generation expansion planning: problem formulation and numerical comparisons', IEEE Transactions on Power Systems 16(4), 885-891.

Couture, Toby \& Yves Gagnon (2010), 'An analysis of feed-in tariff remuneration models: Implications for renewable energy investment', Energy Policy 38(2), 955-965.

Dangl, T (1999), 'Investment and capacity choice under uncertain demand', European Journal of Operational Research 117(3), 415-428.

Devine, Mel T., Niall Farrell \& William T. Lee (2017), 'Optimising feed-in tariff design through efficient risk allocation', Sustainable Energy, Grids and Networks 9, 59 74 .

Dixit, A.K \& R.S Pindyck (1994), Investment Under Uncertainty, Princeton University Press, Princeton, New Jersey.

EIA (2017), Levelized cost and levelized avoided cost of new generation resources in the annual energy outlook 2017, Technical report, U.S. Energy Information Administration.

Kim, Kyoung-Kuk \& Chi-Guhn Lee (2012), 'Evaluation and optimization of feed-in tariffs', Energy Policy 49, 192-203.

Langary, Damoun, Nasser Sadati \& Ali Mohammad Ranjbar (2014), 'Direct approach in computing robust nash strategies for generating companies in electricity markets', Electrical Power and Energy Systems 54, 442-453. 
McDonald, Robert \& Daniel Siegel (1986), 'The value of waiting to invest', The Quarterly Journal of Economics 101(707-728).

Merton, Robert C. (1973), 'Theory of rational option pricing', The Bell Journal of Economics and Management Science 4(1), 141-183.

Murphy, F. \& Y. Smeers (2005), 'Generation capacity expansion in imperfectly competitive restructured electricity markets', Operations Research 53(4), 646-661.

Myers, S.C (1977), 'Determinants of corporate borrowing', Journal of Financial Economics 5, 147-175.

Nanduri, Vishnu, Tapas K. Das \& Patricio Rocha (2009), 'Generation capacity expansion in energy markets using a two-level game-theoretic model', IEEE Transactions on Power Systems 24(3), 1165 - 1172.

Pirnia, Mehrdad, Jatin Nathwani \& David Fuller (2011), 'Ontario feed-in-tariffs: System planning implications and impacts on social welfare', The Electricity Journal $\mathbf{2 4}(8), 18-28$.

REN21 (2018), Renewables 2018 global status report, Technical report, Paris: REN21 Secretariat.

Rocha, Katia, Luciana Salles, Francisco A A Garcia, José Alberto Sardinha \& José Paulo Teixeira (2007), 'Real estate and real options - a case study', Emerging Markets Review 8(67-79).

Sun, Peng \& Pu yan Nie (2015), 'A comparative study of feed-in tariff and renewable portfolio standard policy in renewable energy industry', Renewable Energy 74, 255 -262 .

Tamás, Mészáros Mátyás, S.O. Bade Shrestha \& Huizhong Zhou (2010), 'Feed-in tariff and tradable green certificate in oligopoly', Energy Policy 38(8), 4040 - 4047.

Tourinho, Octavio Augusto Fontes (1979), The valuation of reserves of natural resources: an option pricing approach, $\mathrm{PhD}$ thesis, University of California, Berkeley.

Twomey, Paul \& Karsten Neuhoff (2010), 'Wind power and market power in competitive markets', Energy Policy 38, 3198-3210.

Wolfram, Catherine D. (1999), 'Measuring duopoly power in the british electricity spot market', The American Economic Review 89(4), 805-826.

Yamamoto, Yoshihiro (2012), 'Pricing electricity from residential photovoltaic systems: A comparison of feed-in tariffs, net metering, and net purchase and sale', Solar Energy 86(9), $2678-2685$.

Yamamoto, Yoshihiro (2017), 'Feed-in tariffs combined with capital subsidies for promoting the adoption of residential photovoltaic systems', Energy Policy 111, 312 320 .

Yi, Zuo, Zhao Xin-gang, Zhang Yu-zhuo \& Zhou Ying (2019), 'From feed-in tariff to renewable portfolio standards: An evolutionary game theory perspective', Journal of Cleaner Production 213, 1274 - 1289. 